OPEN ACCESS

Edited by:

Danny Horesh,

Bar-llan University, Israel

Reviewed by:

Karni Ginzburg,

Tel Aviv University, Israel

Yael Lahav,

Tel Aviv University, Israel

*Correspondence:

Ann K. Shinn

akshinn@partners.org

Specialty section: This article was submitted to

Psychopathology,

a section of the journal

Frontiers in Psychiatry

Received: 23 April 2019 Accepted: 20 December 2019 Published: 24 February 2020

Citation:

Shinn AK, Wolff JD, Hwang M,

Lebois LAM, Robinson MA, Winternitz SR, Öngür D, Ressler KJ and Kaufman ML (2020) Assessing Voice Hearing in Trauma Spectrum

Disorders: A Comparison of Two

Measures and a Review of the

Literature.

Front. Psychiatry 10:1011

doi: 10.3389/fpsyt.2019.01011

\section{Assessing Voice Hearing in Trauma Spectrum Disorders: A Comparison of Two Measures and a Review of the Literature}

\author{
Ann K. Shinn ${ }^{1,2^{*}}$, Jonathan D. Wolff ${ }^{2,3}$, Melissa Hwang ${ }^{1}$, Lauren A. M. Lebois ${ }^{2,3,4}$, \\ Mathew A. Robinson ${ }^{2,3}$, Sherry R. Winternitz ${ }^{2,3}$, Dost Öngür ${ }^{1,2}$, Kerry J. Ressler $^{2,4}$ \\ and Milissa L. Kaufman ${ }^{2,3}$ \\ ${ }^{1}$ Psychotic Disorders Division, McLean Hospital, Belmont, MA, United States, ${ }^{2}$ Department of Psychiatry, Harvard Medical \\ School, Boston, MA, United States, ${ }^{3}$ Dissociative Disorders and Trauma Research Program, McLean Hospital, Belmont, \\ MA, United States, ${ }^{4}$ Neurobiology of Fear Laboratory, McLean Hospital, Belmont, MA, United States
}

Voice hearing $(\mathrm{VH})$ can occur in trauma spectrum disorders (TSD) such as posttraumatic stress disorder (PTSD) and dissociative disorders. However, previous estimates of VH among individuals with TSD vary widely. In this study, we sought to better characterize the rate and phenomenology of VH in a sample of 70 women with TSD related to childhood abuse who were receiving care in a specialized trauma program. We compared the rate of VH within our sample using two different measures: 1) the auditory hallucination (AH) item in the Structured Clinical Interview for DSM-IV-TR (SCID), and 2) the thirteen questions involving $\mathrm{VH}$ in the Multidimensional Inventory of Dissociation (MID), a self-report questionnaire that comprehensively assesses pathological dissociation. We found that $45.7 \%$ of our sample met threshold for SCID AH, while $91.4 \%$ met criteria for MID VH. Receiver operating characteristics (ROC) analyses showed that while SCID AH and MID $\mathrm{VH}$ items have greater than chance agreement, the strength of agreement is only moderate, suggesting that SCID and MID VH items measure related but not identical constructs. Thirty-two patients met criteria for both SCID AH and at least one MID VH item ("unequivocal VH"), 32 for at least one MID VH item but not SCID AH ("ambiguous VH"), and 6 met criteria for neither ("unequivocal non-VH"). Relative to the ambiguous $\mathrm{VH}$ group, the unequivocal $\mathrm{VH}$ group had higher dissociation scores for child voices, and higher mean frequencies for child voices and Schneiderian voices. Our findings suggest that VH in women with TSD related to childhood abuse is common, but that the rate of VH depends on how the question is asked. We review prior studies examining $\mathrm{AH}$ and/or $\mathrm{VH}$ in TSD, focusing on the measures used to ascertain these experiences, and conclude that our two estimates are consistent with previous studies that used comparable instruments and patient samples. Our results add to growing evidence that $\mathrm{VH}$-an experience typically considered psychotic or psychotic-like-is not equivalent to having a psychotic disorder. Instruments that assess VH apart from psychotic disorders and that capture 
their multidimensional nature may improve identification of $\mathrm{VH}$, especially among patients with non-psychotic disorders.

Keywords: voice hearing, auditory hallucinations, posttraumatic stress disorder, dissociative disorders, psychosis, phenomenology, assessment

\section{INTRODUCTION}

Voice hearing $(\mathrm{VH})$ is the experience of hearing voices in the absence of corresponding external stimuli. VH is typically considered a hallucinatory experience and is most frequently associated with disorders on the schizophrenia spectrum. However, VH is not specific to schizophrenia or related psychotic disorders (1-3). 'Psychosis' is a broad term referring to some degree of loss of contact with reality. Psychosis includes sensory experiences of things that are not physically present or beliefs that are not based in reality, among other experiences. Experiencing psychosis symptoms is not necessarily equivalent to having a psychotic disorder. Indeed, though $\mathrm{VH}$ is typically considered a psychotic symptom, $\mathrm{VH}$ occurs in many nonpsychotic conditions [e.g., mood $(4,5)$, trauma-related $(6-10)$, personality $(11,12)$, substance-related, and neurological (13-15) disorders], as well as in 'healthy' individuals (16-21).

Trauma is a common experience. Up to $89.7 \%$ of adults have experienced at least one lifetime traumatic event (22), and up to $38.8 \%$ of the general population have experienced adversity in childhood (23). It is well-documented that trauma, and especially childhood trauma, increases the risk of both psychotic disorders and psychosis, including hallucinatory experiences [e.g., Read et al. (24) for review]. A meta-analysis aggregating data from almost 80,000 patients estimated an odds ratio of 2.78 (95\% CI 2.34-3.31) for the association between childhood adversity and psychosis (25). This meta-analysis included studies that measured psychosis as a dimensional outcome (e.g., psychotic symptoms, including subclinical psychotic experiences, in the general population) as well as studies with diagnostic measures of psychosis (i.e., psychotic disorders such as schizophrenia). In fact, studies have shown a dose-response effect between cumulative childhood adversities and risk of psychosis (26-29) and hallucinations in specific (30-32). In one study, the odds of auditory hallucinations were 2.4 after one, 9.1 after two, and 7.6 after three adverse events (32). In particular, rape and physical abuse before age 16 were found to be associated with a 6 -fold and 4-fold increase in auditory hallucinations, respectively (32).

Posttraumatic stress disorder (PTSD) and dissociative identity disorder (DID) are considered trauma spectrum disorders, or disorders strongly linked to trauma exposure. PTSD is characterized by persistent intrusions (e.g., flashbacks, nightmares), avoidance of trauma related stimuli, mood and cognitive alterations, and hyperarousal following exposure to one or more traumatic events (33). DID is generally conceptualized as a post-traumatic syndrome that is etiologically related to severe trauma in childhood $(34,35)$. DID is characterized by the presence of two or more personality states, resulting in discontinuities of experience, sense of self, and self-agency
(33). Identity states are believed to reflect disruptions in the psychological integration of traumatic and non-traumatic aspects of self (36), and symptoms include gaps in memory, depersonalization, derealization, and dissociative intrusions. While DID is technically not included in the Diagnostic and Statistical Manual of Mental Disorders $5^{\text {th }}$ Revision (DSM-5) chapter on trauma and stressor-related disorders, there is substantial evidence that complex dissociative disorders like DID and dissociative disorder not otherwise specified (DDNOS; now called Other Specified Dissociative Disorder in the DSM-5) are post-traumatic responses to childhood trauma. Studies that have systematically examined the etiology of DID have found antecedent severe, chronic childhood trauma in almost every individual with this diagnosis $(37,38)$. Dissociative disorders are therefore described in the DSM-5 chapter that immediately follows the trauma and stressorrelated disorders chapter, acknowledging the close relationship between DID and traumatic antecedents. Given this foundational body of work, we use the term trauma spectrum disorders (TSD) in this paper to refer to both PTSD and DID.

Multiple reports have documented the occurrence of $\mathrm{VH}$ in both PTSD (7, 39-48) (Table 1A) and dissociative disorders (810, 34, 49-60) (Table 1B). According to an early study of auditory hallucinations in combat-related chronic PTSD, voices were frequently related to trauma experienced during combat (e.g., voices of soldiers the veteran had killed or witnessed the death of), could be heard inside or outside the head, frequently commanded self-harm, were often crying or criticizing, and were relatively refractory to treatments (39). In another study of $\mathrm{VH}$ among chronic PTSD patients, half recognized the identity of the voices, a third experienced voices that commanded self-harm, $89 \%$ identified their voices as being inside their head, and half reported voices being as clear and loud as the researcher's voice (46). Consistent with prior studies $(41,91)$, the authors found that the content of voices was often symbolically or thematically related to trauma but that the voices were distinct from representations in memory of experienced events, such as flashbacks (46). The few studies that have directly compared the phenomenology of $\mathrm{VH}$ in trauma spectrum vs. schizophrenia spectrum disorders, though limited by small sample sizes, have shown that patients with TSD experience voices that are as frequent $(6,92)$, and as vivid and real as in schizophrenia (6). Similarly, loudness, negative content, and/or distress due to voices have been reported to be similar (92) or even more severe $(6,93)$ in TSD compared to schizophrenia.

While VH appears to be associated with significant morbidity in many individuals with TSD, the scope of the problem remains unclear, as estimates of VH prevalence in TSD vary widely (Table 1A, B). Some studies report VH in as many as $85 \%$ of 
TABLE 1A | Studies of voice hearing in Posttraumatic Stress Disorder (PTSD).

\begin{tabular}{|c|c|c|c|c|c|c|c|c|c|c|}
\hline & Study & $\begin{array}{l}\text { Size of } \\
\text { Dx } \\
\text { Sample }\end{array}$ & Female & Sample & Trauma history & Study Setting & $\begin{array}{l}\text { Diagnostic } \\
\text { Assessment }\end{array}$ & $\begin{array}{l}\text { Voice } \\
\text { Hearing } \\
\text { Measure }\end{array}$ & $\begin{array}{l}\text { Operational Definition/ } \\
\text { Description of Voice Hearing }\end{array}$ & $\begin{array}{l}\text { Voice Hearing } \\
\text { Rate }\end{array}$ \\
\hline 1 & $\begin{array}{l}\text { Mueser } \\
\text { and Butler } \\
\text { (39) }\end{array}$ & $N=36$ & $0 \%$ & $\begin{array}{l}\text { Combat veterans with PTSD } \\
\text { (mean age } 38.8 \text { years) who } \\
\text { showed no psychotic symptoms } \\
\text { other than } \mathrm{AH} \text { (in } n=5 \text { ) }\end{array}$ & Combat, adulthood & $\begin{array}{l}\text { Inpatient unit at a } \\
\text { VA Medical Center } \\
\text { in California, USA }\end{array}$ & $\begin{array}{l}\text { DSM-III } \\
\text { criteria and } \\
\text { MMPI (61) }\end{array}$ & $\begin{array}{l}\text { "Clinical } \\
\text { interviews" }\end{array}$ & $\begin{array}{l}\text { Not specified (but abstract and intro } \\
\text { briefly relate AH to "intrusive } \\
\text { auditory perceptions," possibly } \\
\text { analogous to intrusive images) }\end{array}$ & 13.9\% $\mathrm{AH}$ \\
\hline 2 & $\begin{array}{l}\text { Wilcox et } \\
\text { al (40) }\end{array}$ & $N=59$ & $0 \%$ & $\begin{array}{l}\text { Combat veterans with PTSD, } \\
\text { consecutively treated at clinic in a } \\
\text { 3-month period (mean age of } \\
\text { sample not specified) }\end{array}$ & Combat, adulthood & $\begin{array}{l}\text { VA outpatient clinic } \\
\text { in Texas, USA }\end{array}$ & $\begin{array}{l}\text { DSM-III } \\
\text { criteria }\end{array}$ & Not specified & $\begin{array}{l}\text { Not specified (but abstract } \\
\text { mentions "intrusive auditory } \\
\text { perceptions") }\end{array}$ & $\begin{array}{l}28.9 \% \text { life } \\
\text { prevalence of } \mathrm{AH}\end{array}$ \\
\hline 3 & $\begin{array}{l}\text { Butler et al } \\
(41)\end{array}$ & $N=20$ & $0 \%$ & $\begin{array}{l}38 \text { Vietnam-era veterans, not } \\
\text { treatment-seeking, with verifiable } \\
\text { combat experience in the armed } \\
\text { forces }(n=20 \text { with PTSD, mean } \\
\text { age } 40.2 \text { years, and } n=18 \\
\text { without PTSD, mean age } 40.9 \\
\text { years). Exclusion criteria included } \\
\text { suspected schizophrenia, } \\
\text { psychosis, or major affective } \\
\text { disorder. }\end{array}$ & Combat, adulthood & $\begin{array}{l}\text { Veterans' center in } \\
\text { California, USA }\end{array}$ & $\begin{array}{l}\text { DSM-III-R } \\
\text { criteria and } \\
\text { M-PTSD }\end{array}$ & $\begin{array}{l}\text { SAPS } \\
\text { hallucinations } \\
\text { subscale }\end{array}$ & $\begin{array}{l}\text { SAPS hallucinations subscale } \\
\text { assesses for AH ("Have you heard } \\
\text { voices or other sounds when no } \\
\text { one is around?"), voices } \\
\text { commenting ("Have you ever heard } \\
\text { voices commenting on what you } \\
\text { are thinking or doing?"), voices } \\
\text { conversing ("Have you heard two or } \\
\text { more voices talking with each } \\
\text { other?"), somatic or tactile } \\
\text { hallucinations, olfactory } \\
\text { hallucinations, visual hallucinations, } \\
\text { and a global rating of hallucination } \\
\text { severity. Study authors summed } \\
\text { individual subscale items (not } \\
\text { including global ratings). }\end{array}$ & $\begin{array}{l}25.0 \% \text { with } \\
\text { mild-moderate } \\
\text { hallucinations } \\
\text { (prevalence of } \\
\text { individual } \\
\text { hallucination items, } \\
\text { including } \mathrm{AH} \text { or } \\
\text { first rank } \\
\mathrm{VH}, \text { not specified) }\end{array}$ \\
\hline 4 & $\begin{array}{l}\text { David et al } \\
\text { (42) }\end{array}$ & $N=53$ & $0 \%$ & $\begin{array}{l}\text { Veterans with chronic combat- } \\
\text { related PTSD (mean age 46.9y) } \\
\text { consecutively admitted }\end{array}$ & Combat, adulthood & $\begin{array}{l}\text { Inpatient PTSD } \\
\text { rehab unit in } \\
\text { Florida, USA }\end{array}$ & $\begin{array}{l}\text { SCID for } \\
\text { DSM-III-R } \\
\text { and M-PTSD }\end{array}$ & $\begin{array}{l}\text { SCID for } \\
\text { DSM-III-R }\end{array}$ & $\begin{array}{l}\text { SCID DSM-III-R B35: "Did you ever } \\
\text { hear things that other people } \\
\text { couldn't hear, such as noises, or } \\
\text { the voices of people whispering or } \\
\text { talking? (Were you awake at the } \\
\text { time?)" } \\
\text { Per study authors, hallucinations } \\
\text { were rated as psychotic if not } \\
\text { accompanied by the perception of } \\
\text { being back in the traumatic } \\
\text { situation/flashbacks and if there } \\
\text { was at least momentary } \\
\text { disturbance in reality testing. }\end{array}$ & $37.7 \% \mathrm{AH}$ \\
\hline 5 & $\begin{array}{l}\text { Hamner et } \\
\text { al (43) }\end{array}$ & $N=45$ & $0 \%$ & $\begin{array}{l}\text { Vietnam combat veterans with } \\
\text { PTSD but without a primary } \\
\text { psychotic disorder seeking } \\
\text { treatment in a PTSD clinic }(n=22 \\
\text { with psychotic features, mean age } \\
52.5 \text { years, and } n=23 \text { without } \\
\text { psychotic features, mean age } \\
51.1 \text { years). Patients were } \\
\text { considered to have psychotic }\end{array}$ & Combat, adulthood & $\begin{array}{l}\text { Outpatient PTSD } \\
\text { clinic in } \\
\text { South Carolina, } \\
\text { USA }\end{array}$ & $\begin{array}{l}\text { CAPS and } \\
\text { SCID for } \\
\text { DSM-III-R }\end{array}$ & $\begin{array}{l}\text { SCID for } \\
\text { DSM-III-R } \\
\text { psychosis } \\
\text { screening } \\
\text { module and } \\
\text { PANSS }\end{array}$ & $\begin{array}{l}\text { SCID DSM-III-R B35 (see above). } \\
\text { Per study authors, symptoms } \\
\text { occurring only during a flashback or } \\
\text { dissociative episode were not } \\
\text { counted as psychotic features. }\end{array}$ & $46.7 \% \mathrm{AH}$ \\
\hline
\end{tabular}




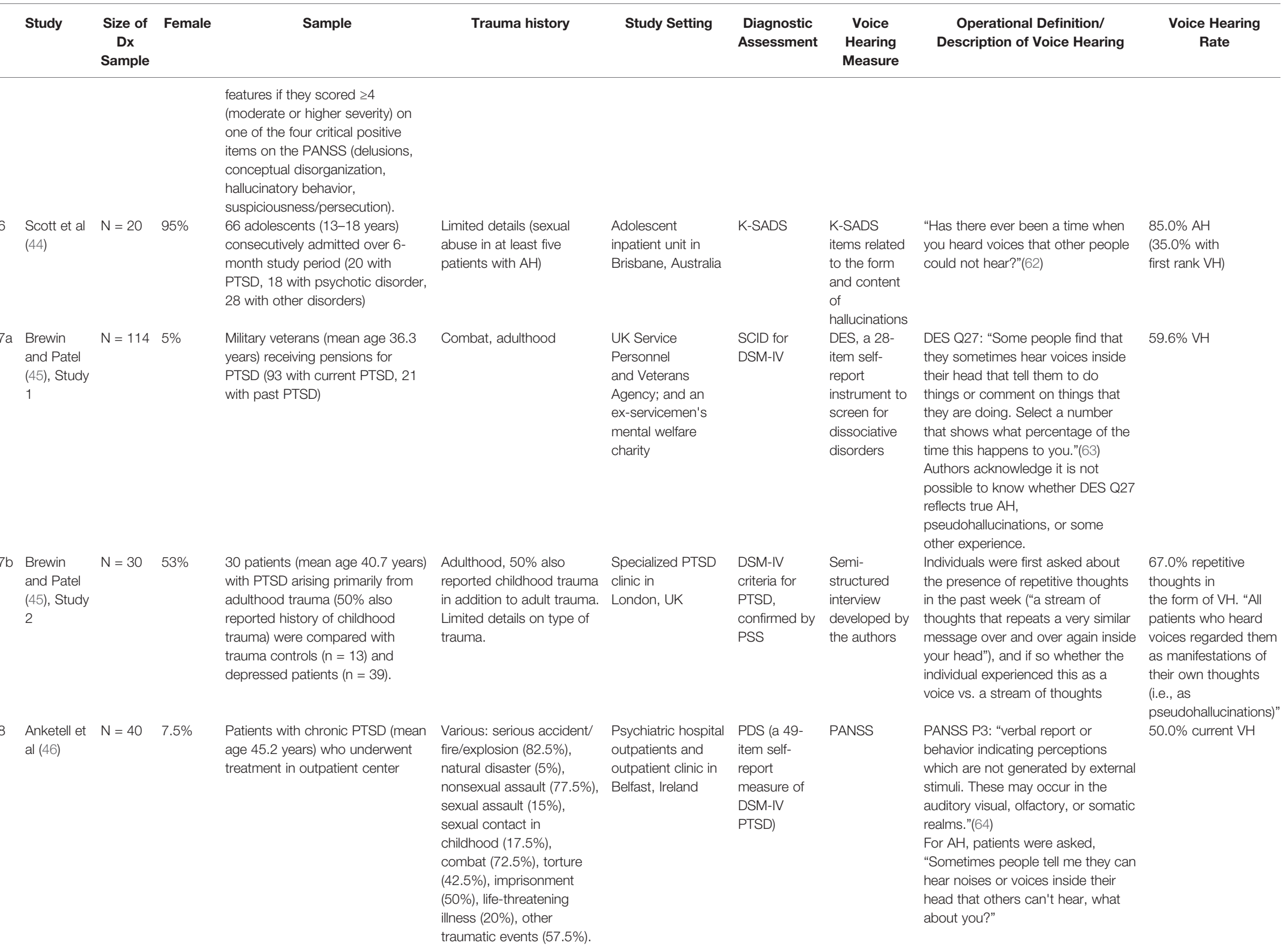


between childhood versus

adult trauma except for

childhood sexual contact.

9 Nygaard $\mathrm{N}=181 \quad 425 \% \quad$ Trauma-affected refugees (mean et al (47) age 44.9 years) with PTSD with (n $=74$ PTSD-SP) and without ( $\mathrm{n}=$ 107 PTSD) secondary psychotic

features

$36.4 \%$ PTSD),

imprisonment (59.5\%

psychiatric

unit and treatmen

Capter in the

Iived in a war zone $(85.1 \%$ Capital Region,

PTSD-SP, 82.2\% PTSD), Denmark

lived in a refugee camp

(25.6\% PTSD-SP, 24.3\%

PTSD), soldier in war

(31.1\% PTSD-SP, 21.5\%

PTSD

10 Crompton $\mathrm{N}=61 \quad 0 \%$ et al (7)

11 Clifford et $N=40 \quad N o$ Not Adult survivors of physical and

al $(48)$ $(n=40$, mean age 34.4 years) $(n=40$, mean age 34.4 years
were compared with healthy

Israeli male veterans from the

Trauma related to being POW, e.g., solitary

confinement, torture

Veterans in Israel contacted by prisoners of war (POW) (mean age confinement, torture
53 years) with PTSD $(n=61)$ were
(sexual and physical lephone and compared with ex-POW's with abuse; deprivation of food, PSD $(n=36)$ and veteran water, and medical in a longitudinal controls (no POW status) without treatment), verbal and PTSD $(n=96) \quad$ psychological abuse. psychological abuse.
Captivity ranged from 1.5 to 8 months.

control participants $(n=39$, mean

hysical and sexual

abuse.

47.5\% reported trauma both childhood and psychiatric disorders in adulthood. referral center in

Paddington,

London, UK ( $\mathrm{n}=$ 15) or from a

database of

approximately 2,000 community volunteers recruited via local newspaper advertisements, maintained by the Medical Research Council Cognition and Brain Science research group at the University of Cambridge, UK ( $\mathrm{n}$ = 25). records specified, but patients with PTSD

with secondary psychotic feature (PTSD-SP) defined: 1) psychotic symptoms had to be experienced while awake. 2) Experiences described in relation to sleep (hypnogogic/hypnopompic) not included. 3) Patients with intact reality testing included. (4) Patients with flashbacks connected to psychotic or psychotic-like symptoms were included in the study.

SCL-90-R SCL-90-R Q16: "In the past week, how much were you bothered by hearing words that others could not hear?"(66)

9.8\% $\mathrm{AH}$ at time 1 (18 years post-war); (30 years post-war)

SCID for

"Auditory

pseudo-

Individuals were first asked about the presence of repetitive thoughts,

5.0\% "auditory

hallucinations and if so whether the individua

pseudo-

interview experienced this as a voice vs. a hallucinations" used in Study stream of thoughts

2 by Brewin DES-II Q27: "Some people

and Patel (45) sometimes find that they heor (45), and voices inside their head that tell

DES-II things that they are doing. Circle the number to show what $>10 \%$ of the time on DES-II Q27, selfreport) $45.0 \% \mathrm{VH}>10 \%$ of the time on DES-II Q27, semi-structured percentage of the time this happens to you."(67) 


\begin{tabular}{|c|c|c|c|c|c|c|c|c|c|c|}
\hline & Study & $\begin{array}{l}\text { Size of } \\
\text { Dx } \\
\text { Sample }\end{array}$ & Female & Sample & Trauma history & Study Setting & $\begin{array}{l}\text { Diagnostic } \\
\text { Assessment }\end{array}$ & $\begin{array}{l}\text { Voice Hearing } \\
\text { Measure }\end{array}$ & $\begin{array}{c}\text { Operational Definition/Description } \\
\text { of Voice Hearing }\end{array}$ & $\begin{array}{l}\text { Voice Hearing } \\
\text { Rate }\end{array}$ \\
\hline 1 & Bliss (49) & $N=11$ & $100 \%$ & $\begin{array}{l}\text { Patients with multiple } \\
\text { personalities (mean age } 30 \\
\text { years) who were identified by } \\
\text { relatives or friends }\end{array}$ & $\begin{array}{l}\text { Little to no details } \\
\text { on trauma history } \\
\text { (one patient may } \\
\text { have been raped) }\end{array}$ & $\begin{array}{l}14 \text { individuals with } \\
\text { multiple } \\
\text { personalities that } \\
\text { the author-a } \\
\text { physician in an } \\
\text { academic } \\
\text { psychiatry } \\
\text { department in Salt } \\
\text { Lake City, Utah, } \\
\text { USA-encountered } \\
\text { and studied in the } \\
\text { previous year. }\end{array}$ & $\begin{array}{l}\text { "All had } \\
\text { personalities who } \\
\text { revealed } \\
\text { themselves and } \\
\text { their missions } \\
\text { under hypnosis." } \\
\text { No other criteria for } \\
\text { diagnosis specified. }\end{array}$ & $\begin{array}{l}713 \text {-item self-report } \\
\text { questionnaire developed } \\
\text { by the author } \\
\text { (completed by only } 11 \\
\text { of the } 14 \text { total patients) }\end{array}$ & Not specified & $\begin{array}{l}64 \% \\
\text { "schizophrenia" } \\
\text { voices }\end{array}$ \\
\hline 2 & Bliss (50) & $\mathrm{N}=70$ & $68.6 \%$ & $\begin{array}{l}\text { Adult patients with multiple } \\
\text { personalities (mean age not } \\
\text { specified) }\end{array}$ & $\begin{array}{l}\text { Sexual and physical } \\
\text { abuse "when } \\
\text { young" ( } 60 \% \text { of } \\
\text { female and } 27 \% \text { of } \\
\text { male patients } \\
\text { reported early } \\
\text { sexual abuse; } 40 \% \\
\text { of female and } 32 \% \\
\text { of male patients } \\
\text { reported early } \\
\text { physical abuse). }\end{array}$ & $\begin{array}{l}\text { Research setting } \\
\text { unspecified; } \\
\text { however, author } \\
\text { with affiliation with } \\
\text { an academic } \\
\text { psychiatry } \\
\text { department in Salt } \\
\text { Lake City, Utah, } \\
\text { USA. }\end{array}$ & $\begin{array}{l}\text { DSM-III criteria for } \\
\text { MPD ( } n=20 \\
\text { females, } n=12 \\
\text { males), or } \\
\text { determined under } \\
\text { hypnosis to have } \\
\text { "possible multiples" } \\
\text { even if DSM-III } \\
\text { criteria not fully met } \\
\text { ( } n=28 \text { females, } 10 \\
\text { males). NB: As } \\
\text { there were no } \\
\text { significant clinical } \\
\text { differences } \\
\text { observed between } \\
\text { the DSM-III and } \\
\text { possible multiples } \\
\text { patients, the two } \\
\text { groups were } \\
\text { combined for } \\
\text { analysis. }\end{array}$ & $\begin{array}{l}327 \text {-item self-report } \\
\text { questionnaire developed } \\
\text { by the author } \\
\text { (consisting of items from } \\
\text { the Research Diagnostic } \\
\text { Criteria, the MMPI, the } \\
\text { literature, and other } \\
\text { sources) }\end{array}$ & Not specified & $\begin{array}{l}51.4 \% \text { AH } \\
(54 \% \text { in } \\
\text { females, } \\
45 \% \text { in males) }\end{array}$ \\
\hline 3 & $\begin{array}{l}\text { Putnam et al } \\
\text { (51) }\end{array}$ & $\begin{array}{l}N= \\
100\end{array}$ & $92 \%$ & $\begin{array}{l}\text { Outpatients (mean age } 35.8 \\
\text { years) identified by their } \\
\text { treating clinician to have a } \\
\text { diagnosis of MPD }\end{array}$ & $\begin{array}{l}\text { Childhood trauma: } \\
\text { sexual abuse } \\
(83 \%), \text { physical } \\
\text { abuse }(75 \%) \text {, } \\
\text { extreme neglect } \\
(60 \%) \text {, witness to } \\
\text { violent death } \\
(\sim 42 \%), \text { extreme } \\
\text { poverty (20\%), and } \\
\text { "other abuses" } \\
(\sim 37 \%) \text {. }\end{array}$ & $\begin{array}{l}\text { Questionnaires } \\
\text { distributed } \\
\text { to } \sim 400 \text { clinicians } \\
\text { across North } \\
\text { America who } \\
\text { previously indicated } \\
\text { an interest in MPD. } \\
\text { Each clinician was } \\
\text { asked to report on } \\
\text { a single patient, } \\
\text { currently or recently } \\
\text { in treatment with } \\
\text { that clinician, who }\end{array}$ & $\begin{array}{l}\text { DSM-III criteria for } \\
\text { MPD (criteria were } \\
\text { specified on the } \\
\text { cover page of the } \\
\text { questionnaire, but } \\
\text { "the interpretation } \\
\text { of these criteria } \\
\text { was left to the } \\
\text { reporting clinician, } \\
\text { since no } \\
\text { independent } \\
\text { confirmation was } \\
\text { possible.") }\end{array}$ & $\begin{array}{l}\text { 386-item questionnaire } \\
\text { developed by the } \\
\text { authors, including a 73- } \\
\text { item checklist of signs } \\
\text { and symptoms } \\
\text { observed by the } \\
\text { clinician or reported by } \\
\text { the patient during } \\
\text { clinician's initial contacts } \\
\text { with the patient }\end{array}$ & Not specified & $30 \% \mathrm{AH}$ \\
\hline
\end{tabular}




\begin{tabular}{|c|c|c|c|c|c|c|c|c|c|c|}
\hline \multicolumn{2}{|r|}{ Study } & $\begin{array}{l}\text { Size of } \\
\text { Dx } \\
\text { Sample }\end{array}$ & Female & Sample & Trauma history & Study Setting & $\begin{array}{l}\text { Diagnostic } \\
\text { Assessment }\end{array}$ & $\begin{array}{l}\text { Voice Hearing } \\
\text { Measure }\end{array}$ & $\begin{array}{l}\text { Operational Definition/Description } \\
\text { of Voice Hearing }\end{array}$ & $\begin{array}{l}\text { Voice Hearing } \\
\text { Rate }\end{array}$ \\
\hline & & & & & & $\begin{array}{l}\text { met } \\
\text { DSM-III criteria for } \\
\text { MPD. Return rate } \\
\text { was } 40 \% .100 \\
\text { cases were } \\
\text { selected based on } \\
\text { the number of } \\
\text { questions } \\
\text { completed } \\
\text { (submitted by } 92 \\
\text { clinicians, including } \\
49 \text { psychiatrists, } 37 \\
\text { PhD clinical } \\
\text { psychologists, and } \\
6 \text { MSW psychiatric } \\
\text { social workers). }\end{array}$ & & & & \\
\hline 4 & $\begin{array}{l}\text { Coons and } \\
\text { Milstein (52) }\end{array}$ & $N=20$ & $85 \%$ & $\begin{array}{l}20 \text { patients with MPD (mean } \\
\text { age } 29 \text { years) diagnosed by } \\
\text { the first author, compared } \\
\text { with } 20 \text { age and sex- } \\
\text { matched inpatients with } \\
\text { primarily affective and } \\
\text { characterologic disturbances } \\
\text { and without schizophrenia or } \\
\text { dissociative disorders }\end{array}$ & $\begin{array}{l}\text { Childhood sexual } \\
\text { (75\%) and physical } \\
\text { abuse (55\%). } \\
\text { Childhood abuse } \\
\text { and/or rape } \\
\text { confirmed by at } \\
\text { least one family } \\
\text { member or } \\
\text { emergency room } \\
\text { report in } 17 \\
\text { patients (85\%) }\end{array}$ & $\begin{array}{l}\text { Patients with MPD } \\
\text { receiving treatment } \\
\text { at an academically } \\
\text { affiliated psychiatric } \\
\text { hospital in } \\
\text { Indianapolis, IN, } \\
\text { USA ( } n=10 \\
\text { outpatient, } n=9 \\
\text { inpatient, } n=1 \\
\text { from the } \\
\text { consultation-liaison } \\
\text { service) who were } \\
\text { seen by the first } \\
\text { author during an } \\
11 \text {-year period. }\end{array}$ & $\begin{array}{l}\text { DSM-III criteria for } \\
\text { MPD }\end{array}$ & $\begin{array}{l}\text { Psychiatric interview } \\
\text { (unstructured) and } \\
\text { MMPI }\end{array}$ & Not specified & $60 \% \mathrm{AH}$ \\
\hline 5 & Kluft (53) & $N=30$ & $70 \%$ & $\begin{array}{l}\text { Patients with MPD (mean } \\
\text { age not specified) who were } \\
\text { determined to have achieved } \\
\text { and maintained (for } 27 \\
\text { months or more) fusion of } \\
\text { personalities. Of } 241 \text { MPD } \\
\text { interviewed patients, } 135 \\
\text { were excluded for not having } \\
\text { achieved fusion of } \\
\text { personalities, } 54 \text { for not } \\
\text { maintaining fusion } 27 \text { months } \\
\text { or more, } 11 \text { for "relapse } \\
\text { phenomena," } 4 \text { for requiring } \\
\text { psychiatric medications, and } \\
7 \text { for other reasons, leaving }\end{array}$ & Not specified & $\begin{array}{l}\text { Referrals to the } \\
\text { author- } \\
\text { a physician affiliated } \\
\text { with a psychiatric } \\
\text { hospital in } \\
\text { Philadelphia, PA, } \\
\text { USA-for } \\
\text { consideration or } \\
\text { confirmation of the } \\
\text { diagnosis of MPD. }\end{array}$ & $\begin{array}{l}\text { DSM-III criteria for } \\
\text { MPD }\end{array}$ & $\begin{array}{l}\text { Data from the author's } \\
\text { first interview with each } \\
\text { patient }\end{array}$ & $\begin{array}{l}\text { Author conducted interviews using } \\
\text { Mellor's first rank symptom } \\
\text { definitions(68) (including for audible } \\
\text { thoughts) and "generally employ } \\
\text { [ing]" interview questions from } \\
\text { Carpenter et al(69), with } \\
\text { modifications. NB: the author } \\
\text { "evolved novel questions" for } \\
\text { voices arguing and voices } \\
\text { conversing (exact questions not } \\
\text { specified) }\end{array}$ & $\begin{array}{l}46.7 \% \text { first- } \\
\text { rank } \mathrm{AH} \\
\text { (33.3\% voices } \\
\text { arguing, } \\
30 \% \text { voices } \\
\text { conversing) }\end{array}$ \\
\hline
\end{tabular}




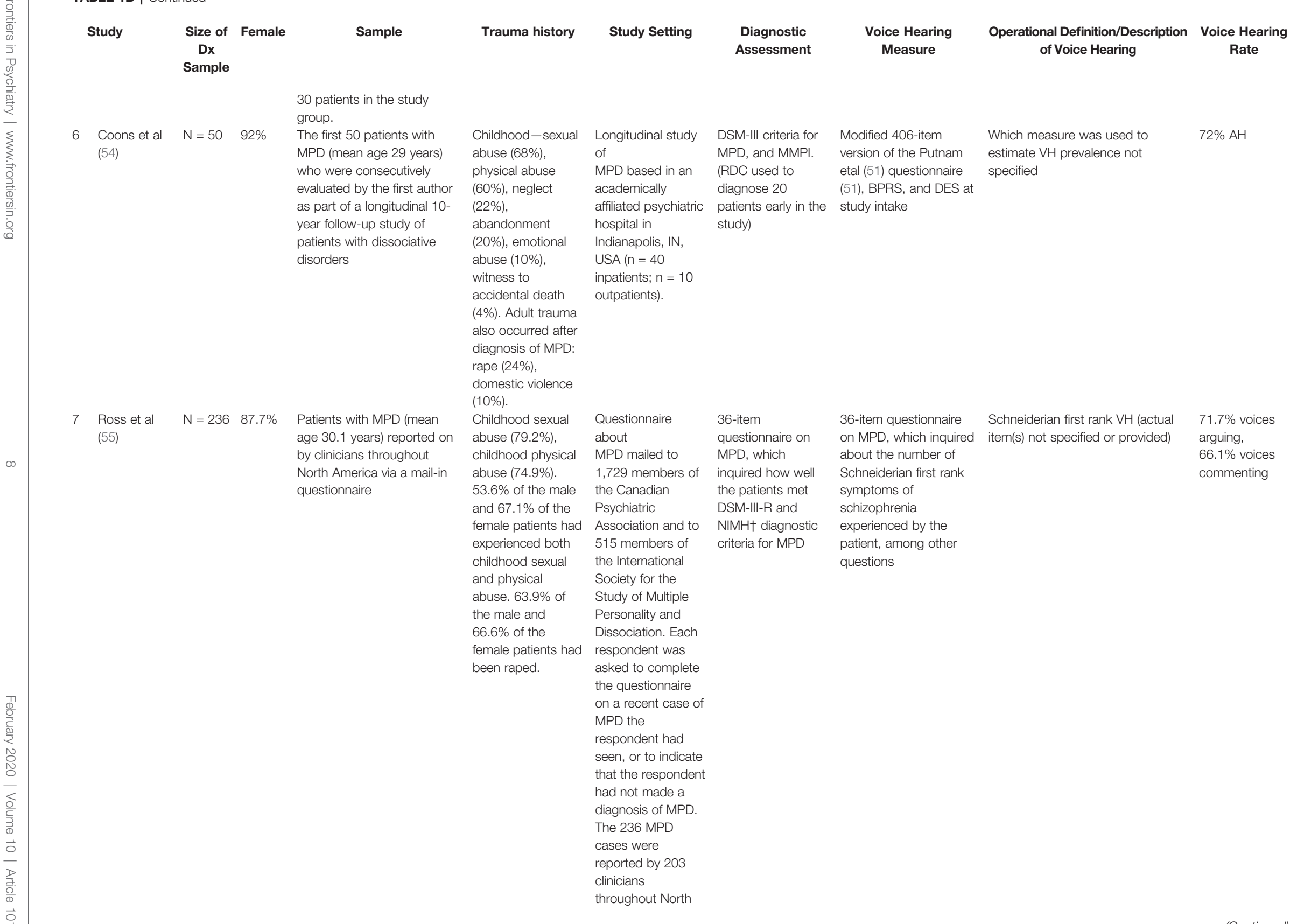




\begin{tabular}{|c|c|c|c|c|c|c|c|c|c|c|}
\hline \multicolumn{2}{|r|}{ Study } & $\begin{array}{l}\text { Size of } \\
\text { Dx } \\
\text { Sample }\end{array}$ & Female & Sample & Trauma history & Study Setting & $\begin{array}{l}\text { Diagnostic } \\
\text { Assessment }\end{array}$ & $\begin{array}{l}\text { Voice Hearing } \\
\text { Measure }\end{array}$ & $\begin{array}{c}\text { Operational Definition/Description } \\
\text { of Voice Hearing }\end{array}$ & $\begin{array}{c}\text { Voice Hearing } \\
\text { Rate }\end{array}$ \\
\hline & & & & & & $\begin{array}{l}\text { America (including } \\
\text { psychiatrists, non- } \\
\text { psychiatric MD's, } \\
\text { psychologists, } \\
\text { social workers, } \\
\text { nurses, } \\
\text { occupational } \\
\text { therapists, and } \\
\text { "other") }\end{array}$ & & & & \\
\hline 8 & $\begin{array}{l}\text { Ross et al } \\
(56)\end{array}$ & $N=102$ & $90.2 \%$ & $\begin{array}{l}\text { Patients with clinical } \\
\text { diagnoses of MPD (mean } \\
\text { age } 31.8 \text { years) }\end{array}$ & $\begin{array}{l}\text { Childhood sexual } \\
(90.2 \%) \text { and } \\
\text { physical abuse } \\
(82.4 \%) \text {. Altogether, } \\
95.1 \% \text { of patients } \\
\text { had experienced } \\
\text { one or both forms } \\
\text { of childhood } \\
\text { trauma. }\end{array}$ & $\begin{array}{l}\text { Four medical } \\
\text { centers } \\
\text { in North America: } \\
\text { Winnipeg ( } \mathrm{n}=50 \text {; } \\
\text { patients presenting } \\
\text { for initial } \\
\text { assessment), Utah } \\
\text { ( } \mathrm{n}=20 \text {; patients } \\
\text { participating as } \\
\text { subjects for a PhD } \\
\text { thesis), California ( } \mathrm{n} \\
\text { = 17; patients } \\
\text { presenting for initial } \\
\text { assessment), and } \\
\text { Ottawa ( } \mathrm{n}=15 ; \\
\text { patients drawn } \\
\text { from an existing } \\
\text { caseload, primarily } \\
\text { therapy } \\
\text { outpatients). No } \\
\text { differences } \\
\text { between centers on } \\
\text { demographics or } \\
\text { mean number of } \\
\text { Schneiderian } \\
\text { symptoms } \\
\text { endorsed. }\end{array}$ & $\begin{array}{l}\text { Clinical interview } \\
\text { and DDIS (131-item } \\
\text { structured interview } \\
\text { that takes } 30- \\
45 \text { min to } \\
\text { administer; } \\
\text { sensitivity } 90 \% \text { and } \\
\text { specificity } 100 \% \text { for } \\
\text { MPD diagnosis(70, } \\
71 \text { ) }\end{array}$ & $\begin{array}{l}\text { DDIS section on } \\
\text { secondary features of } \\
\text { MPD } \\
\text { Note: in a } \\
\text { complementary paper } \\
\text { by Ross et al (1990) } \\
\text { (72), the DDIS section } \\
\text { on positive symptoms } \\
\text { of schizophrenia } \\
\text { (Schneiderian first rank } \\
\text { symptoms) is used to } \\
\text { estimate VH in the same } \\
\text { sample of } 102 \text { MPD } \\
\text { patients }\end{array}$ & $\begin{array}{l}\text { DDIS Q96: "Do you hear voices } \\
\text { talking to you sometimes or talking } \\
\text { inside your head?" } \\
\text { DDIS Q64: "Have you ever } \\
\text { experienced the following: a) voices } \\
\text { arguing in your head, b) voices } \\
\text { commenting on your actions..." } \\
\text { (DDIS also asks if Schneiderian } \\
\text { symptoms have occurred only } \\
\text { under the influence of drugs or } \\
\text { alcohol, or only during a major } \\
\text { depressive episode.) }\end{array}$ & $\begin{array}{l}\text { 87.3\% voices } \\
\text { talking (Q96) } \\
78.4 \% \text { voices } \\
\text { arguing, } \\
81.4 \% \text { voices } \\
\text { commenting } \\
\text { (Q64)(72) }\end{array}$ \\
\hline 9 & $\begin{array}{l}\text { Loewenstein } \\
\text { and Putnam } \\
\text { (34) }\end{array}$ & $N=21$ & $0 \%$ & $\begin{array}{l}21 \text { male patients with MPD } \\
\text { (mean age } 38.6 \text { years) were } \\
\text { compared with data on } 92 \\
\text { female patients previously } \\
\text { collected for a different study } \\
\text { on MPD (which used } \\
\text { questionnaires mailed to } \\
\text { outpatient clinicians across } \\
\text { North America)(51). }\end{array}$ & $\begin{array}{l}\text { Childhood-sexual } \\
\text { abuse (85\%), } \\
\text { physical abuse } \\
(\sim 95 \%), \text { neglect } \\
\text { ( } 66 \%), \text { extreme } \\
\text { poverty ( } 34 \% \\
\text { male), witness to } \\
\text { violence }(\sim 0 \% \\
\text { male), other trauma } \\
\text { (93\% male, } 85 \%\end{array}$ & $\begin{array}{l}\text { Referrals for } \\
\text { dissociative } \\
\text { disorder } \\
\text { consultation to the } \\
\text { two authors. Most } \\
\text { patients came from } \\
\text { the clinical services } \\
\text { of a Veterans Affairs } \\
\text { Medical Center in } \\
\text { West Los Angeles, }\end{array}$ & $\begin{array}{l}\text { DSM-III/DSM-III-R } \\
\text { and NIMH† } \\
\text { research criteria for } \\
\text { MPD }\end{array}$ & $\begin{array}{l}\text { 386-item NIMH } \\
\text { questionnaire (clinician- } \\
\text { rated) describing } \\
\text { characteristics of the } \\
\text { patients(51) }\end{array}$ & Not specified & $\begin{array}{l}75 \% \mathrm{AH} \\
\text { (vs. 30\% } \\
\text { in females) }\end{array}$ \\
\hline
\end{tabular}




\begin{tabular}{|c|c|c|c|c|c|c|c|c|c|c|}
\hline \multicolumn{2}{|c|}{ Study } & $\begin{array}{l}\text { Size of } \\
\text { Dx } \\
\text { Sample }\end{array}$ & Female & Sample & Trauma history & Study Setting & $\begin{array}{l}\text { Diagnostic } \\
\text { Assessment }\end{array}$ & $\begin{array}{l}\text { Voice Hearing } \\
\text { Measure }\end{array}$ & $\begin{array}{c}\text { Operational Definition/Description } \\
\text { of Voice Hearing }\end{array}$ & $\begin{array}{c}\text { Voice Hearing } \\
\text { Rate }\end{array}$ \\
\hline & & & & & $\begin{array}{l}\text { female), i.e. } \\
\text { confinement, } \\
\text { emotional abuse, } \\
\text { etc. }\end{array}$ & $\begin{array}{l}\text { CA (patients of } \\
\text { RJL), or from a } \\
\text { federally operated } \\
\text { psychiatric hospital } \\
\text { in Washington, DC } \\
\text { (patients of FWP), } \\
\text { USA, although it is } \\
\text { noted that several } \\
\text { patients also came } \\
\text { from other private } \\
\text { and public settings. }\end{array}$ & & & & \\
\hline 10 & $\begin{array}{l}\text { Dell and } \\
\text { Eisenhower } \\
\text { (57) }\end{array}$ & $N=11$ & $64 \%$ & $\begin{array}{l}\text { Adolescents with MPD } \\
\text { (mean age } 14.7 \text { years) } \\
\text { followed in therapy by the } \\
\text { first author }\end{array}$ & $\begin{array}{l}\text { Childhood - sexual } \\
\text { abuse (73\%), } \\
\text { physical abuse } \\
(73 \%), \text { emotional } \\
\text { abuse ( } 82 \%) \text {, } \\
\text { medical/surgical } \\
\text { trauma (9\%), injury } \\
\text { (9\%). Mean number } \\
\text { of different types of } \\
\text { trauma (i.e. sexual, } \\
\text { physical, and } \\
\text { emotional abuse, } \\
\text { injury, medical/ } \\
\text { surgical trauma) } \\
\text { reported was } 2.4 \\
\text { (range, } 1 \text { to 4). } \\
\text { Trauma and abuse } \\
\text { was confirmed in } \\
73 \% \text { of the cases. }\end{array}$ & $\begin{array}{l}\text { Referrals for } \\
\text { diagnostic } \\
\text { evaluation and/or } \\
\text { therapy to the first } \\
\text { author, a clinical } \\
\text { psychologist } \\
\text { affiliated with an } \\
\text { academic medical } \\
\text { center in Norfolk, } \\
\text { VA, USA, over a 4- } \\
\text { year period }\end{array}$ & $\begin{array}{l}\text { DSM-III-R criteria } \\
\text { plus NIMH† } \\
\text { research criteria for } \\
\text { MPD }\end{array}$ & $\begin{array}{l}\text { Clinical interviews } \\
\text { involving patients and } \\
\text { their families }\end{array}$ & Not specified & $\begin{array}{l}81.8 \% \text { " } \mathrm{AH} \\
\text { (voices heard } \\
\text { within the } \\
\text { head)" }\end{array}$ \\
\hline 11 & $\begin{array}{l}\text { Hornstein } \\
\text { and Putnam } \\
\text { (58) }\end{array}$ & $N=64$ & $65.6 \%$ & $\begin{array}{l}\text { Children and adolescents } \\
\text { with dissociative disorders ( } \mathrm{n} \\
=44 \mathrm{MPD} \text {, mean age } 11.1 \\
\text { years; } \mathrm{n}=20 \text { DDNOS, mean } \\
\text { age } 8.4 \text { years) }\end{array}$ & $\begin{array}{l}\text { Childhood - sexual } \\
\text { abuse (about 57\% } \\
\text { DDNOS, } 80 \% \\
\text { MPD), physical } \\
\text { abuse (about 64\% } \\
\text { DDNOS, 69\% } \\
\text { MPD), both sexual } \\
\text { and physical abuse } \\
\text { (about 50\% } \\
\text { DDNOS, 61\% } \\
\text { MPD), witnessed } \\
\text { violence (about } \\
\text { 80\% DDNOS, 70\% } \\
\text { MPD), neglect } \\
\text { (abOut 63\% } \\
\text { DDNOS, 80\% }\end{array}$ & $\begin{array}{l}\text { First series, } \\
\text { collected } \\
\text { by the first author, } \\
\text { consisted of } \\
\text { patients ( } \mathrm{n}=22 \\
\text { MPD, } n=8 \text { DDNOS) } \\
\text { seen for evaluation } \\
\text { and treatment in an } \\
\text { inpatient unit } \\
\text { (except four } \\
\text { outpatients) at } \\
\text { UCLA in Los } \\
\text { Angeles, CA, USA. } \\
\text { Second series, } \\
\text { collected by the } \\
\text { second author, }\end{array}$ & $\begin{array}{l}\text { DSM-III-R criteria } \\
\text { augmented by } \\
\text { NIMH† criteria for } \\
\text { MPD. } \\
\text { The DSM-III-R } \\
\text { DDNOS diagnosis } \\
\text { lacks specific } \\
\text { criteria; DDNOS } \\
\text { diagnosis was } \\
\text { given to cases in } \\
\text { whom there were } \\
\text { no clear-cut alter } \\
\text { personalities but in } \\
\text { whom there was } \\
\text { observable } \\
\text { dissociation }\end{array}$ & $\begin{array}{l}\text { Database developed by } \\
\text { the authors to } \\
\text { standardize data } \\
\text { collection between the } \\
\text { two sites. The database } \\
\text { consisted of more than } \\
100 \text { symptoms and } \\
\text { behaviors grouped into } \\
16 \text { factors, one of which } \\
\text { was hallucinations. }\end{array}$ & Not specified & $\begin{array}{l}\text { AH in: } \\
-97 \% \text { of } \\
\text { MPD } \\
-75 \% \text { of } \\
\text { DDNOS } \\
\text { Command } \\
\text { hallucinations } \\
\text { in: } \\
-60 \% \text { of MPD } \\
-25 \% \text { of } \\
\text { DDNOS } \\
\text { "Voices urge } \\
\text { violence" in: } \\
-41 \% \text { of MPD } \\
-5 \% \text { of DDNOS }\end{array}$ \\
\hline
\end{tabular}




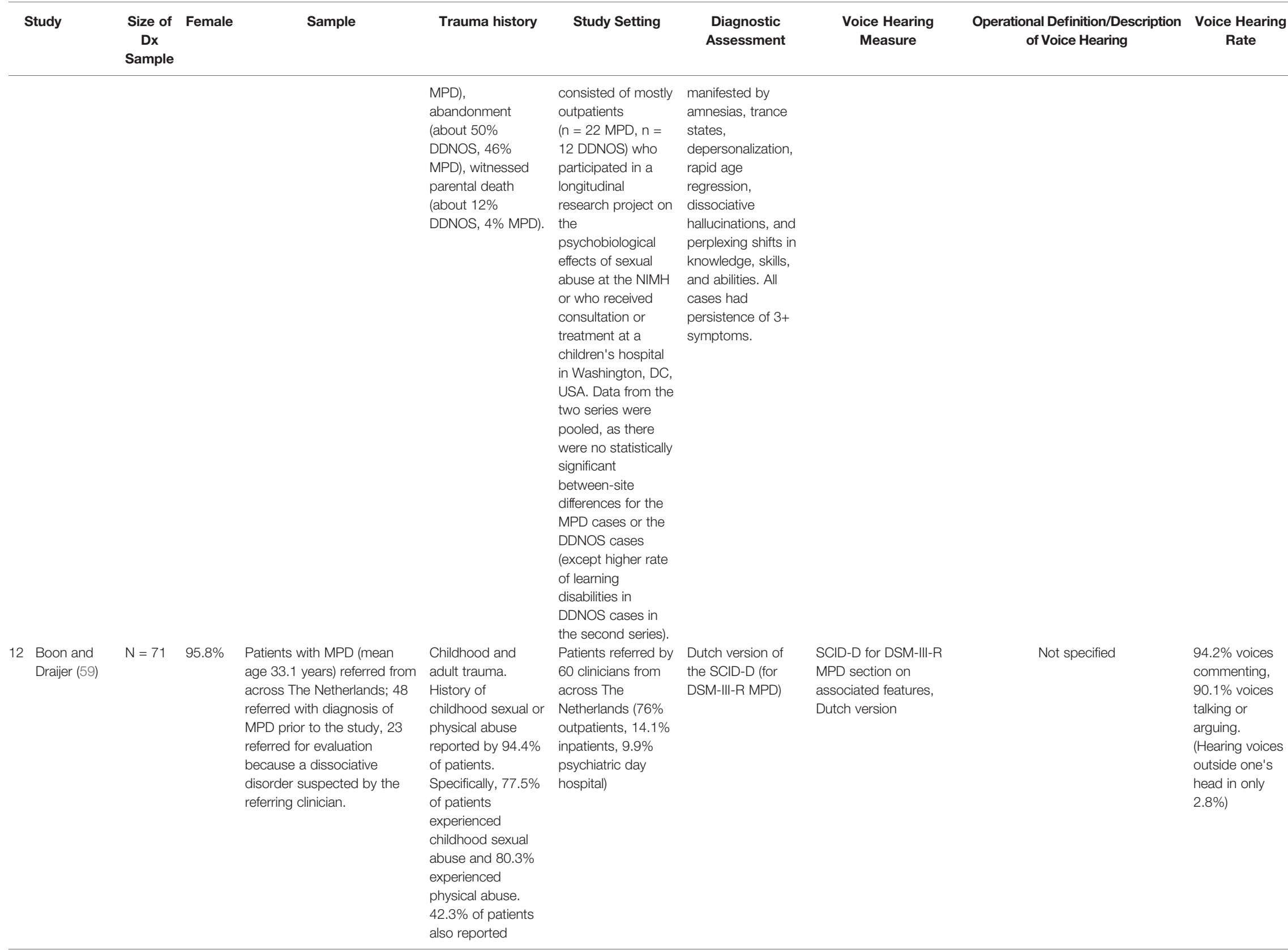




\begin{tabular}{|c|c|c|c|c|c|c|c|c|c|c|}
\hline & Study & Size of & Female & Sample & Trauma history & Study Setting & Diagnostic & Voice Hearing & Operational Definition/Description & Voice Hearing \\
\hline & & & & & $\begin{array}{l}\text { sexual and physical } \\
\text { abuse in adulthood } \\
\text { (individual rates not } \\
\text { specified) }\end{array}$ & & & & & \\
\hline 13 & Sar et al (8) & $N=35$ & $88.6 \%$ & $\begin{array}{l}\text { Turkish patients with clinical } \\
\text { diagnoses of DID (mean age } \\
22.8 \text { years) }\end{array}$ & $\begin{array}{l}\text { Childhood trauma: } \\
\text { physical abuse } \\
(62.9 \%), \text { sexual } \\
\text { abuse ( } 57.1 \%) \text {, } \\
\text { neglect }(62.9 \%) \text {, } \\
\text { emotional abuse } \\
(57.1 \%) .77 .1 \% \text { of } \\
\text { the patients } \\
\text { experienced one or } \\
\text { both physical and } \\
\text { sexual abuse. } \\
88.6 \% \text { of patients } \\
\text { experienced at } \\
\text { least one type of } \\
\text { childhood trauma } \\
\text { listed above. }\end{array}$ & $\begin{array}{l}\text { Medical center } \\
\text { (including in- and } \\
\text { outpatient } \\
\text { psychiatric } \\
\text { services) at the } \\
\text { University of } \\
\text { Istanbul, Turkey }\end{array}$ & $\begin{array}{l}\text { DSM-IV criteria for } \\
\text { DID, and } n=29 \\
(82.9 \%) \text { met criteria } \\
\text { for MPD on the } \\
\text { Turkish version of } \\
\text { the DDIS (sensitivity } \\
95 \% \text { and specificity } \\
98.3 \% \text { ) }\end{array}$ & $\begin{array}{l}\text { Turkish versions of } \\
\text { DDIS and DES }\end{array}$ & $\begin{array}{l}\text { DDIS Q96: "Do you hear voices } \\
\text { talking to you sometimes or talking } \\
\text { inside your head?" }\end{array}$ & $\begin{array}{l}94.3 \% \text { "voices } \\
\text { talking" }\end{array}$ \\
\hline 14 & Coons (60) & $N=25$ & $84 \%$ & $\begin{array}{l}\text { Children ( } n=4 \text { DDNOS) and } \\
\text { adolescents ( } n=11 \text { MPD, } n \\
=9 \text { DDNOS, } n=1 \\
\text { psychogenic amnesia) with } \\
\text { DSM-III-R dissociative } \\
\text { disorders who were } \\
\text { consecutively referred for } \\
\text { diagnostic evaluation (mean } \\
\text { age of the } 4 \text { children was } 8.5 \\
\text { years, range } 5-12 \text { years; } \\
\text { mean age of the } 21 \\
\text { adolescents was } 15.8 \text { years, } \\
\text { range } 13-17 \text { years) }\end{array}$ & $\begin{array}{l}\text { Childhood sexual } \\
(76 \%) \text { and physical } \\
\text { abuse }(68 \%) . \text { Child } \\
\text { abuse confirmed in } \\
8 \text { of the } 9 \text { cases of } \\
\text { MPD and in } 12 \\
\text { cases of DDNOS. }\end{array}$ & $\begin{array}{l}\text { Referrals ( } \mathrm{n}=10 \\
\text { outpatient, } \mathrm{n}=11 \\
\text { inpatient) for } \\
\text { diagnostic } \\
\text { evaluation by a } \\
\text { specialized } \\
\text { dissociative } \\
\text { disorders clinic at a } \\
\text { psychiatric hospital } \\
\text { in Indianapolis, IN, } \\
\text { USA between } \\
\text { 1984-1993 }\end{array}$ & $\begin{array}{l}\text { DSM-III-R criteria } \\
\text { for MPD. } \\
\text { DDNOS was } \\
\text { diagnosed in cases } \\
\text { similar to MPD that } \\
\text { failed to meet full } \\
\text { diagnostic criteria } \\
\text { for MPD. }\end{array}$ & $\begin{array}{l}\text { Adolescents: DES and } \\
\text { MMPI (in inpatients) } \\
\text { Children: CDC } \\
\text { completed by parents }\end{array}$ & $\begin{array}{l}\text { Exactly how VH was defined or } \\
\text { measured not specified }\end{array}$ & $\begin{array}{l}\text { "Inner voices" } \\
\text { reported by: } \\
-100 \% \text { of } \\
\text { adolescents } \\
\text { with MPD } \\
-77 \% \text { of } \\
\text { adolescents } \\
\text { with DDNOS } \\
-50 \% \text { of } \\
\text { children with } \\
\text { DDNOS }\end{array}$ \\
\hline 15 & $\begin{array}{l}\text { Middleton } \\
\text { and Butler } \\
\text { (9) }\end{array}$ & $N=62$ & $87 \%$ & $\begin{array}{l}\text { Patients with DID (mean age } \\
31.6 \text { years) }\end{array}$ & $\begin{array}{l}\text { Childhood/ } \\
\text { adolescent sexual } \\
\text { abuse (87\%), } \\
\text { physical abuse } \\
\text { (85\%), emotional } \\
\text { abuse }(79 \%) \text {. } \\
\text { Confirmation of } \\
\text { significant past } \\
\text { trauma was } \\
\text { obtained for 29\% } \\
\text { of patients via } \\
\text { actual admissions } \\
\text { from principal }\end{array}$ & $\begin{array}{l}\text { Patients seen over } \\
\text { a 5-year period } \\
\text { (1992-1997) by } \\
\text { either of the two } \\
\text { authors, who were } \\
\text { affiliated with a } \\
\text { university and a } \\
\text { private psychiatric } \\
\text { hospital in } \\
\text { Queensland, } \\
\text { Australia. } \\
\text { Assessments were } \\
\text { not part of a formal }\end{array}$ & $\begin{array}{l}\text { DSM-IV criteria for } \\
\text { DID, DDIS, and } \\
\text { DES }\end{array}$ & $\begin{array}{l}\text { DDIS, DES, and clinical } \\
\text { interviews }\end{array}$ & $\begin{array}{l}\text { Exactly how VH was defined or } \\
\text { measured not specified }\end{array}$ & $\begin{array}{l}98 \% \text { "auditory } \\
\text { hallucinations or } \\
\text { pseudo- } \\
\text { hallucinations." } \\
\text { Both } \\
\text { internalized and } \\
\text { externalized } \\
\text { voices were } \\
\text { experienced in } \\
\text { the majority (at } \\
\text { least } 67 \% \text {; } \\
\text { unspecified } \\
14 \%)\end{array}$ \\
\hline
\end{tabular}




\begin{tabular}{|c|c|c|c|c|c|c|c|c|c|}
\hline Study & $\begin{array}{l}\text { Size of } \\
\text { Dx } \\
\text { Sample }\end{array}$ & Female & Sample & Trauma history & Study Setting & $\begin{array}{l}\text { Diagnostic } \\
\text { Assessment }\end{array}$ & $\begin{array}{l}\text { Voice Hearing } \\
\text { Measure }\end{array}$ & $\begin{array}{l}\text { Operational Definition/Description } \\
\text { of Voice Hearing }\end{array}$ & $\begin{array}{c}\text { Voice Hearing } \\
\text { Rate }\end{array}$ \\
\hline 6 Dell (10) & $\begin{array}{l}N= \\
220\end{array}$ & $90 \%$ & $\begin{array}{l}\text { Patients clinically diagnosed } \\
\text { with DID (mean age } 41 \\
\text { years) and undergoing active } \\
\text { psychotherapy }\end{array}$ & $\begin{array}{l}\text { abusers, other } \\
\text { family members, } \\
\text { photographic } \\
\text { evidence, and } \\
\text { medical or police } \\
\text { records. }\end{array}$ & $\begin{array}{l}\text { research project. } \\
\text { The clinical settings } \\
\text { were diverse (i.e., } \\
\text { acute hospital } \\
\text { admissions, } \\
\text { inpatient or } \\
\text { outpatient referrals, } \\
\text { medical ward } \\
\text { consultations, civil } \\
\text { and criminal } \\
\text { medicolegal } \\
\text { evaluations, etc.). } \\
\text { Outpatient settings } \\
\text { ( } n=161 \text { ) } \\
\text { throughout the } \\
\text { USA and Canada; } \\
\text { inpatient facilities ( } \mathrm{n} \\
=57 \text { ) in the USA } \\
\text { (California, Texas, } \\
\text { Massachusetts), } \\
\text { Canada, and } \\
\text { Australia; clinical } \\
\text { setting of } n=2 \\
\text { unknown. }\end{array}$ & $\begin{array}{l}\text { Clinically diagnosed } \\
\text { by therapist to have } \\
\text { DSM-IV DID. } \\
\text { Diagnosis } \\
\text { confirmed with } \\
\text { SCID-D-R in a } \\
\text { subset }(n=41) \text {. }\end{array}$ & $\begin{array}{l}\text { 259-item precursor of } \\
\text { the final version of the } \\
\text { MID (with } 218 \text { items) }\end{array}$ & See Table 2 & $\begin{array}{l}95 \% \text { voices } \\
\text { commenting, } \\
89 \% \text { voices } \\
\text { arguing }\end{array}$ \\
\hline
\end{tabular}

AH, auditory hallucinations; BPRS, Brief Psychiatric Rating Scale (73); CAPS, Clinician Administered PTSD Scale (74); CDC, Child Dissociation Checklist (75); DDIS, Dissociative Disorders Interview Schedule (70, 71); DDNOS, Dissociative disorder not otherwise specified; DES, Dissociative Experiences Scale (63); DES-II, Dissociative Experiences Scale, version II (67); DSM, Diagnostic and Statistical Manual of Mental Disorders [e.g., DSM-III (76), DSM-IV (77)]; K-SADS, Kiddie Schedule for Affective Disorders and Schizophrenia for School Aged Children (62); MID, Multidimensional Inventory of Dissociation (78); MMPI, Minnesota Multiphasic Personality Inventory (79); MPD, Multiple Personality Disorder; M-PTSD, Mississippi Scale for Combat-Related Posttraumatic Stress Disorder (80): PANSS, Positive and Negative Syndrome Scale (64): PDS, Posttraumatic Stress Diagnostic Scale (81): PSS, Posttraumatic Stress Scale (82): PTSD-I, Posttraumatic Stress Disorder Inventory (83); RDC, Research Diagnostic Criteria (84); SAPS, Scale for the Assessment of Positive Symptoms (85); SADS-C, Schedule for Affective Disorders and Schizophrenia, Change Version (86); SCID, Structured Clinical Interview for DSM [SCID for DSM-III-R (87), SCID for DSM-IV (88)]; SCID-D, Structured Clinical interview for DSM-III-R Dissociative Disorders (89); SCID-D-R, Structured Clinical interview for DSM-IV Dissociative Disorders-Revised (90); SCL90-R, Symptom Checklist 90, Revised (66); VH, voice hearing.

tThe National Institute of Mental Health (NIMH) research criteria for MPD specified that, in addition to DSM-III or DSM-III-R criteria for MPD being satisfied, two or more alter personalities had to exhibit distinct alter personality-specific behavior on at least three separate occasions, and that psychogenic amnesia was reported or observed(34). 
PTSD patients (44) and in $90 \%$ or more of individuals with DID (8-10, 58-60), suggesting that the experience of $\mathrm{VH}$ may potentially be the rule rather than the exception in TSD. Other studies, however, report rates as low as 5\% in PTSD (48) and 30\% in DID (51).

The wide range of estimates may be due, in part, to differences in the types of patients who were sampled. Rates and experiences of $\mathrm{VH}$ may differ according to the individual's sex, age, specific type of trauma, timing of exposure to trauma within the developmental lifespan, level of overall clinical acuity at the time of assessment, and broader cultural factors, among others. Most studies of $\mathrm{VH}$ in PTSD have been conducted in male combat veterans $(7,39-43,45,46)$. Fewer studies have examined $\mathrm{VH}$ in mostly women $(44)$ or mixed sex civilian samples $(45,47,48)$ with PTSD. (Conversely, females are disproportionately represented among individuals who are diagnosed with dissociative disorders, and this sex discrepancy is reflected in the existing literature.) Further, while exposure to severe physical and sexual abuse in early childhood have been prominent themes in the dissociative disorders literature, there are no studies examining $\mathrm{VH}$ in individuals with PTSD primarily related to trauma in childhood.

Studies also vary considerably with respect to how $\mathrm{VH}$ or hallucinations in TSD are ascertained. Numerous studies provide little to no details about how VH was defined or measured $(9,34$, $39,40,51,52,54,57,58,60)$; in some cases, the lack of specific details may be due to the fact that estimating the prevalence of $\mathrm{VH}$, per se, was not many studies' primary objective. Along similar lines, several studies, especially earlier studies, used less rigorous methods for ascertaining $\mathrm{VH}$, such as unstructured interviews $(39,40,52,53,57,58)$, medical records review (47), or measures that have not been well-studied or validated $(49,50$, 53). Among the PTSD and dissociative disorders studies that measured VH more systematically, some [e.g., $(7,50,52)]$ used instruments designed to assess a broad range of psychopathology such as the Minnesota Multiphasic Personality Inventory (MMPI) (79). Others $(8-10,45,56,59,60)$ measured VH using instruments designed to assess dissociative symptomatology, such as the Dissociative Experiences Scale (DES) (63) or DES-II (67). Still others (41-44, 46) measured auditory hallucinations using instruments designed to evaluate symptoms associated with schizophrenia spectrum disorders, such as the Positive and Negative Syndrome Scale (PANSS) (64) or the psychotic disorders module of the Structured Clinical Interview for DSM (SCID) (87).

Importantly, the nature of VH in PTSD and DID is not well understood and warrants further exploration. It is unclear if the experience of $\mathrm{VH}$ in trauma-related disorders reflects perceptual abnormalities as appears to be the case in psychotic disorders, hearing the voices of different identity state intrusions in DID, and/or something else entirely (10). It has been proposed that $\mathrm{VH}$ in non-psychotic disorders as well as in the general population may be more dissociative rather than psychotic (2, 94) and, thus, different from the perceptual abnormalities experienced by individuals with schizophrenia. On the other hand, a small literature suggests there is significant phenomenological overlap between $\mathrm{VH}$ experiences in schizophrenia and trauma-related disorders $(6,92,93)$. Still other researchers have proposed that $\mathrm{VH}$ is entirely dissociative in nature (94); according to this more radical view, auditory hallucinations are a symptom of dissociation even in schizophrenia. Given the limited understanding about the phenomenology of $\mathrm{VH}$ in TSD, how a specific item asks about $\mathrm{VH}$ or auditory hallucinations-for example, how a question is worded, and the specific context in which the question is askedis likely to be critical in influencing how an individual responds, and in determining $\mathrm{VH}$ prevalence.

This investigation sought to better characterize the phenomenology and rate of $\mathrm{VH}$ in a sample of adult female patients with PTSD related to childhood abuse and neglect who were receiving care at a specialized PTSD treatment center. We sought to estimate the proportion of individuals with $\mathrm{VH}$ in our sample using two different instruments-one that is traditionally used to diagnose schizophrenia and related psychotic disorders, and the other representing a model of pathological dissociation. The goal was to investigate how much the estimates of $\mathrm{VH}$ rate differ with the two measures, and to examine whether the measures differ in clinically or phenomenologically meaningful ways.

\section{METHODS}

\section{Participants and Procedures}

We studied 73 women with PTSD either recruited from inpatient, residential, partial hospital, and outpatient programs specializing in the treatment of adult women with histories of trauma-related disorders at McLean Hospital $(n=68)$ or referred by affiliated outpatient trauma clinicians $(n=5)$. Patients were recruited as part of a multimodal neuroimaging study evaluating the neurobiology of traumatic dissociation. The study was approved by the institutional review board of McLean Hospital, and all participants provided written informed consent.

To be eligible for the study, participants had to be female, 1889 years in age, have legal and mental competency, meet criteria for PTSD, and have a history of childhood abuse. Individuals meeting criteria for schizophrenia or other psychotic disorders (including bipolar I disorder with psychotic features) were excluded. Exclusion criteria also included alcohol or substance dependence or abuse within the last month, history of neurological conditions that may cause significant psychiatric symptomatology, history of head injury or loss of consciousness longer than five minutes, and delirium secondary to medical illness. As data were originally acquired for a neuroimaging study, individuals with any contraindications to magnetic resonance imaging (e.g., metal implants, pregnancy, claustrophobia, etc.) were also excluded.

We administered the Clinician Administered PTSD Scale for DSM-5 (CAPS-5) (95) to diagnose PTSD, the Structured Clinical Interview for DSM-IV Dissociative Disorders Revised (SCID-D-R) (90) to diagnose DID, the SCID for DSM-IV Axis II personality disorders (SCID-II) (96) to diagnose borderline personality disorder, and the SCID-I for DSM-IV-TR (97) to assess for any other Axis I 
disorders, including schizophrenia and other psychotic disorders. These four semi-structured interviews are considered the gold standard instruments for diagnosing the respective categories of psychiatric disorders. Clinical research interviews were conducted by trained research staff with expertise in trauma spectrum disorders.

In addition to diagnostic interviews, participants completed the Multidimensional Inventory of Dissociation (MID) (78), a 218-item (168 dissociation items and 50 validity items) selfreport questionnaire that comprehensively assesses the phenomenological domains for pathological dissociation. The MID assesses the presence of 23 different dissociative symptoms and is unique in that it inquires about only pathological rather than normative experiences of dissociation (e.g., absorption, hypnotizability, fantasy proneness). For each item, the individual is asked to rate the frequency of experiences using a 0-10 Likert scale in which 0 indicates "never" and 10 "always." Participants are instructed to indicate a number between 0 and 10 that "best describes how often it happens to you." The MID explicitly instructs participants to rate how often each experience occurs when not under the influence of alcohol or drugs. The MID has two scoring systems: mean frequency scores and severe dissociation scores. Severe dissociation scores are based on empirically-determined pass/fail cut-off scores for each item, designed to maximize the discrimination between individuals who have and do not have a severe dissociative disorder (10). The instrument shows excellent internal consistency (Cronbach's alpha $=98$ ), test-retest reliability over 4-8 weeks, construct validity with standardized measures of traumatic stress, and discriminative validity with the SCID-D-R. Structural validity has been confirmed using factor analytic techniques $(78,98)$.

Additional self-report measures completed by participants include the Childhood Trauma Questionnaire (CTQ) (99), a 25item questionnaire that evaluates the frequency of childhood abuse and neglect, the PTSD Checklist for DSM-5 (PCL-5) (100, 101), a 20-item measure that assesses the twenty DSM-5 symptoms of PTSD, and the Beck Depression Inventory (BDI) (102), a 21-item scale that assesses the severity of depression. The CTQ measures the severity of five different types of childhood trauma (emotional, physical, and sexual abuse and emotional and physical neglect). To characterize the specific features of childhood trauma in finer detail, as well as to assess exposure to non-child abuse trauma, we also administered the Traumatic Events Inventory (TEI) (103), which assesses lifetime history of trauma exposure.

We obtained information about demographic characteristics, including age, parental education, and intelligence quotient (IQ) as measured by the Wechsler Abbreviated Scale of Intelligence (WASI-II) (104). We also collected information about psychiatric medications (i.e., antipsychotics, antidepressants, mood stabilizers, and sedative-hypnotics) patients were taking at the time of study participation.

We grouped the patients into one of three $\mathrm{VH}$ categories: unequivocal voice hearers, ambiguous voice hearers, and unequivocal non-voice hearers (described in greater detail below, in the section on "Phenomenological comparison of the unequivocal vs. ambiguous voice hearing groups"). We compared these three groups with respect to demographic and clinical characteristics. All statistical analyses for this study were conducted using SPSS version 24.0. We first evaluated variables for normality with the Shapiro-Wilk test. For continuous variables that were normally distributed, we performed one-way analysis of variance (ANOVA) to test the null hypothesis that at least one of the three groups is different. Statistically significant results from ANOVA were followed by post-hoc pairwise testing using Tukey's honestly significant difference (HSD) test to adjust for multiple comparisons. For continuous variables that did not fit a normal distribution, we conducted the non-parametric KruskalWallis test. Statistically significant between-group differences detected by the Kruskal-Wallis test were followed by post-hoc pairwise comparisons using the Mann-Whitney $U$ test, with $\mathrm{p}$ values Bonferroni adjusted for three pair-wise tests. For categorical variables, we conducted chi-square tests.

\section{Rate of Voice Hearing in PTSD}

We investigated the rate of $\mathrm{VH}$ in PTSD using two different measures:

1. Item B16 (Auditory Hallucinations) in the SCID psychosis module. This item asks, "Did you ever hear things that other people couldn't, such as noises or the voices of people whispering or talking?" Individuals who scored 3 ("threshold or true") were considered to meet criteria for lifetime auditory hallucinations, while individuals with scores of 1 ("absent or false") or 4 ("inadequate information") were considered not to meet threshold for this item. No individuals reported experiences consistent with a score of 2 ("subthreshold") in our sample. To calculate the rate of $\mathrm{VH}$, we calculated the proportion of individuals who scored threshold on B16. In the DSM-IV-TR, items B17 and B18 also assess for auditory hallucinations, specifically about whether voices commented on what the individual was doing or thinking, or whether two or more voices conversed with one another, respectively. However, item $\mathrm{B} 16$ serves as the gatekeeper to items $\mathrm{B} 17$ and B18; that is, an individual must meet criteria for B16 in order to be asked about B17 and B18. As B17 and B18 data are not available for all participants, we did not further analyze these data.

2. MID voice hearing items. The MID contains thirteen questions that inquire about $\mathrm{VH}$ experiences (Table 2). MID Q98, which asks about voices that come from "unusual places" such as the air conditioner or computer, serves as a screen for psychosis. The other twelve items (Q6, Q30, Q42, Q84, Q97, Q118, Q140, Q159, Q171, Q199, Q207, Q216) ask about $\mathrm{VH}$ in the context of pathological dissociation. As mentioned above, the MID uses pass/fail cut-off scores to identify whether an experience was present to a clinically significant degree (78). For the VH items, these cut-off scores are either $\geq 1$ (Q30, Q42, Q98, Q118, Q199) or 2 2 (Q6, Q84, Q97, Q140, Q159, Q171, Q207, Q216). A VH experience was considered to be present (dichotomous, yes or no) to a clinically significant degree if the cut-off threshold was met for that item. We calculated the rate of $\mathrm{VH}$ by 
TABLE 2 | Voice hearing items in the Multidimensional Inventory of Dissociation (MID).

\begin{tabular}{|c|c|c|c|c|c|c|}
\hline \multirow[t]{2}{*}{ Item } & \multirow{2}{*}{$\begin{array}{l}\text { Multidimensional Inventory } \\
\text { of Dissociation (MID) } \\
\text { Voice Hearing Questions }\end{array}$} & \multicolumn{5}{|c|}{$\begin{array}{l}\text { MID Voice Hearing } \\
\text { Category }\end{array}$} \\
\hline & & $\mathrm{SCH}$ & PER & $\mathrm{CHI}$ & INT & Pos \\
\hline Q6 & $\begin{array}{l}\text { "Hearing the voice of a child in your } \\
\text { head." }\end{array}$ & & & $x$ & & \\
\hline Q30 & $\begin{array}{l}\text { "Hearing voices in your head that argue } \\
\text { or converse with one another." }\end{array}$ & $x$ & & & & \\
\hline Q42 & $\begin{array}{l}\text { "Hearing a voice in your head that tries } \\
\text { to tell you what to do." }\end{array}$ & $x$ & & & $x$ & \\
\hline Q84 & $\begin{array}{l}\text { "Hearing a voice in your head that wants } \\
\text { you to hurt yourself." }\end{array}$ & & $x$ & & & \\
\hline Q97 & $\begin{array}{l}\text { "Hearing a lot of noise or yelling in your } \\
\text { head." }\end{array}$ & $x$ & & $x$ & & \\
\hline Q98 & $\begin{array}{l}\text { "Hearing voices, which come from } \\
\text { unusual places (for example, the air } \\
\text { conditioner, the computer, the walls, } \\
\text { etc.), that try to tell you what to do." }\end{array}$ & & & & & \\
\hline Q118 & "Hearing voices crying in your head." & & & $x$ & & \\
\hline Q140 & $\begin{array}{l}\text { "Hearing a voice in your head that calls } \\
\text { you names (for example, wimp, stupid, } \\
\text { whore, slut, bitch, etc.)" }\end{array}$ & $x$ & $x$ & & & \\
\hline Q159 & $\begin{array}{l}\text { "Hearing a voice in your head that wants } \\
\text { you to die." }\end{array}$ & & $x$ & & & \\
\hline Q171 & $\begin{array}{l}\text { "Hearing a voice in your head that calls } \\
\text { you a liar or tells you that certain events } \\
\text { never happened." }\end{array}$ & $x$ & $x$ & & & \\
\hline Q199 & $\begin{array}{l}\text { "Hearing a voice in your head that tells } \\
\text { you to 'shut up'." }\end{array}$ & $x$ & & & $x$ & \\
\hline Q207 & $\begin{array}{l}\text { "Hearing a voice in your head that calls } \\
\text { you no good, worthless, or a failure." }\end{array}$ & $x$ & $x$ & & & \\
\hline Q216 & $\begin{array}{l}\text { "Hearing a voice in your head that is } \\
\text { soothing, helpful, or protective." }\end{array}$ & & & & & $x$ \\
\hline
\end{tabular}

SCH, Schneiderian voices; PER, Persecutory voices; CHI, Child voices; INT, Voices of internal struggle; POS, Positive voices.

identifying the proportion of individuals who met clinically significant criteria for one or more of the $12 \mathrm{MID} \mathrm{VH}$ experiences (exclusive of the psychosis screener, Q98).

Of the 73 patients in the study at the time of analysis, SCID data were missing for two participants and MID data missing for an additional participant. As the primary objective of this project was to compare $\mathrm{VH}$ as measured by SCID B16 versus the MID, we conducted all analyses using only data from the 70 participants for whom both SCID and MID data were available.

\section{Receiver Operating Characteristics (ROC) Curves}

As we observed discrepant rates of VH using SCID B16 and MID $\mathrm{VH}$ items, we sought to examine the relative agreement between SCID B16 and MID VH measures. To do this, we used a receiver operating characteristic (ROC) curve to examine the total dissociation score for the twelve MID VH items (excluding the psychosis screen, Q98) against dichotomized SCID B16 (yes or no) as the outcome variable. The dissociation score for the twelve $\mathrm{VH}$ items reflects the number of pathological $\mathrm{VH}$ symptoms experienced by each individual, and the possible range of $\mathrm{VH}$ dissociation scores was $0-12$.
We additionally examined total $\mathrm{VH}$ frequency, which takes into account the severity of individual items across the full range of the Likert scale, against SCID B16. For this ROC analysis, we took the sum of the frequency ratings across all twelve MID VH items. For items with a cut-off score of $\geq 2$, we recoded the ratings of frequency ( 0 -10 Likert scale) such that ratings $<2$ were equal to 0 , a rating of 2 was equal to 1 , a rating of 3 was equal to 2 , and so on, such that the maximum frequency rating for each item with $\geq 2$ cut-off was 9 . Since there are eight items with cut-off $\geq 2$ that needed to be recoded, the maximum possible sum of the pathological $\mathrm{VH}$ frequencies decreased from the original 120 to 112 .

For both ROC curves, we calculated the area under the curve (AUC), and used a statistical significance threshold of $\mathrm{p}<0.05$ (or a 95\% confidence interval) to reject the null hypothesis that the accuracy of the MID VH items in predicting VH as measured by SCID B16 is due to chance.

\section{Phenomenological Comparison of the Unequivocal vs. Ambiguous Voice Hearing Groups}

We sought to determine whether any phenomenological $\mathrm{VH}$ characteristics distinguished individuals with $\mathrm{VH}$ who met threshold for B16 from those who did not, i.e., whether there were any systematic differences in the quality or severity of $\mathrm{VH}$ experiences among individuals who endorsed any VH. To do this, we separated the patients into three different groups (Figure 1):

1. Trauma patients with unequivocal VH, i.e., those who met threshold for both SCID B16 (Auditory Hallucinations) AND one or more MID VH items (B16+/MID+),

2. Trauma patients with ambiguous $\mathbf{V H}$, i.e., those who did not meet threshold for SCID B16 but did meet clinically significant criteria for one or more MID VH items (B16-/ $\mathrm{MID}+$ ), and

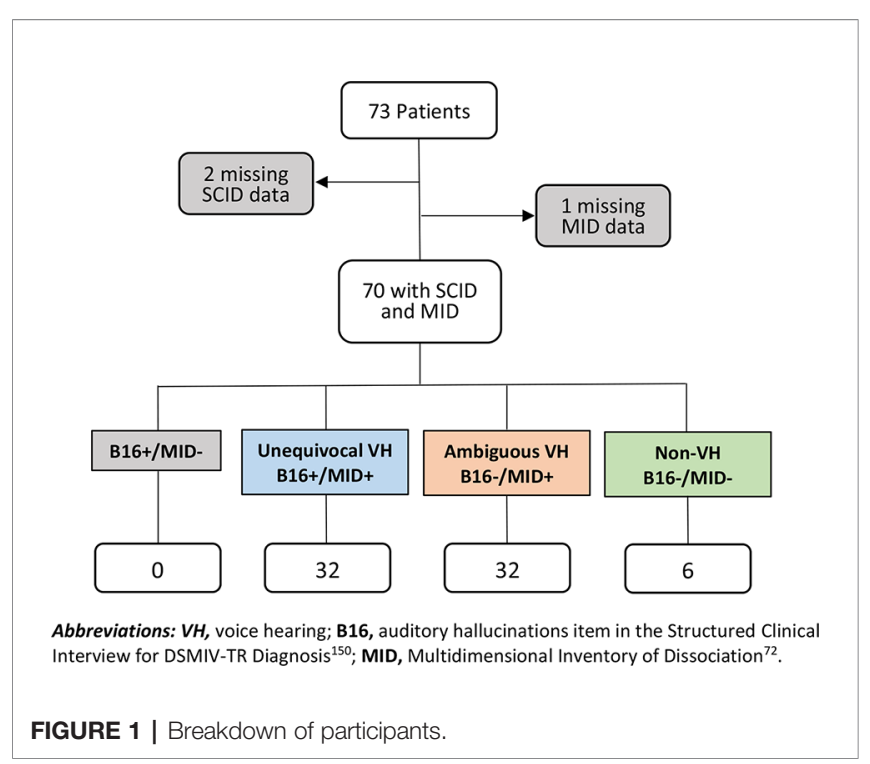


3. Trauma patients who unequivocally denied VH, i.e., those who did not meet threshold for VH by either measure (B16-/ MID-).

There were no individuals who met B16 criteria but did not meet clinically significant criteria for MID VH (B16+/MID-).

We compared the two $\mathrm{VH}$ groups (unequivocal vs. ambiguous $\mathrm{VH}$ groups) with respect to $\mathrm{VH}$ phenomenology, as measured by the MID. The phenomenological categories in the MID related to $\mathrm{VH}$ are voices arguing (Q30), voices commenting (Q42, Q97, Q140, Q171, Q199, Q207), persecutory voices (Q84, Q140, Q159, Q171, Q207), child voices (Q6, Q97, Q118), and helper voices (Q216). Some VH items in the MID appear in more than one VH category (e.g., Q97 is included in both the Schneiderian voices and child voices categories). These MID categories were derived from standard measures of dissociative experiences, interviews with dissociative patients, and theoretical models of pathological dissociation (78). The subscales of the MID were optimized for clinical diagnostic utility, however, principal axis factor analysis in two large datasets (N's >1000) extracted 12 factors that conceptually mapped onto the clinically-optimized subscales of the MID (78). We combined the voices arguing and voices commenting items into a single Schneiderian VH category. The category called "voices/internal struggle" also contains two VH items (Q42, Q199). However, this category includes seven other items not related to $\mathrm{VH}$. Moreover, Q42 and Q99 are already included in the Schneiderian VH category. Therefore, we did not further examine the voices/ internal struggle category. In total, we looked at four phenomenological categories of VH: Schneiderian, persecutory, child, and helper voices.

Mirroring the two scoring systems of the MID instrument, we compared the $\mathrm{VH}$ phenomenology of the two $\mathrm{VH}$ groups using two different approaches. In the first approach, we calculated a dissociation score for each category, which is the number or count of items for which an individual meets clinical significance within a category (e.g., Schneiderian, persecutory, etc.). Whether an individual meets clinical significance for an item is a dichotomous outcome, based on the specific cut-off in the MID for that item. The higher the dissociation score, the greater the number of items in a $\mathrm{VH}$ category an individual has experienced. The maximum possible score for each category varies according to the number of items in each category (i.e., seven items for Schneiderian voices, five items for persecutory voices, three items for child voices, and one item for helper voices). In the second approach, we calculated the mean frequency of pathological $\mathrm{VH}$, which is the mean Likert scale rating of all items within each $\mathrm{VH}$ category. The frequency rating reflects how often someone experiences a particular item; hence, the mean frequency reflects the average of the individual item frequency ratings within a $\mathrm{VH}$ category.

As the dissociation scores and mean frequencies for the four categories of pathological VH were not normally distributed, we conducted the nonparametric Mann-Whitney $\mathrm{U}$ test to test the null hypothesis that the unequivocal $\mathrm{VH}$ and ambiguous $\mathrm{VH}$ groups have equal severity in these $\mathrm{VH}$ measures. Probability values were Bonferroni-adjusted to account for our testing four different $\mathrm{VH}$ categories. We conducted post-hoc analyses to identify which specific item(s) within each category accounted for those between-group differences in $\mathrm{VH}$ categories only for categories found to be statistically significantly different between the two VH groups.

\section{RESULTS}

\section{Participant Characteristics}

As a whole, the patients in this study represent a highly traumatized group. All patients had histories of childhood abuse, as this was a criterion for study inclusion. Of the 66 patients for whom TEI data about child abuse were available, $74 \%$ experienced verbal abuse during childhood; 69\% were beaten or physically punished; $27 \%$ had been attacked by someone with a gun, knife, or other weapon during childhood; $65 \%$ had been attacked by someone without a weapon during childhood; and $83 \%$ were sexually abused in childhood, with $77 \%$ of patients experiencing sexual abuse before the age of 14 (Supplementary Table 1). Patients generally experienced abuse very early in life, starting at approximately 5 years of age on average. Furthermore, the duration of childhood abuse was often prolonged (mean duration 16.5 years for verbal abuse, 10.8 years for beatings, and 8.0 years for sexual abuse during childhood) (Supplementary Table 2). Perpetrators of childhood abuse (specifically verbal abuse, beatings, or sexual abuse) were a primary caregiver in $85 \%$ of cases, other family in $63 \%$, and non-family in $65 \%$ of cases (Supplementary Table 3). Only $20 \%$ of patients had only one abuser during childhood; $80 \%$ reported multiple childhood abusers (mean 2.9, SD 1.5, range 1-7 for $\mathrm{n}=65$ reporting child verbal abuse, beatings, or sexual abuse). Moreover, for most patients, traumatic experiences were not limited to abuse in childhood; patients reported multiple different types of trauma (relational as well as trauma related to natural disasters, serious accident or injury, and sudden lifethreatening illness) during their lifetimes (mean 8.4, SD 3.6, range 2-18 for $\mathrm{n}=67$ for whom any TEI data were available) (Supplementary Table 4). Notably, none of the patients in this sample had trauma from military service or combat.

The three groups-trauma patients with unequivocal $\mathrm{VH}$ (B16+/MID+), trauma patients with ambiguous $\mathrm{VH}$ (B16-/ $\mathrm{MID}+$ ), and trauma patients who unequivocally denied $\mathrm{VH}$ (B16-/MID-)-were comparable with respect to age, IQ, parental education, co-occurring major depressive disorder, cooccurring borderline personality disorder, severity of depressive symptoms, severity of PTSD symptoms, and medication exposure at the time of the study (Table 3 ).

When we assessed for any differences in trauma-related diagnoses between the three $\mathrm{VH}$ groups, we observed a trend for the unequivocal non- $\mathrm{VH}$ group to be characterized by a higher proportion of individuals with PTSD alone (i.e., individuals with neither a dissociative subtype of PTSD nor a diagnosis of a major dissociative disorder in addition to PTSD) $(p=0.065)$. To further explore the possibility that the three $\mathrm{VH}$ groups might be confounded by different trauma-related 
TABLE 3 | Participant characteristics.

\begin{tabular}{|c|c|c|c|c|c|c|}
\hline & All Patients & Unequivocal VH & Ambiguous VH & $\begin{array}{l}\text { Unequivocal } \\
\text { non-VH }\end{array}$ & Statistic & Significance \\
\hline Sample Size & 70 & 32 & 32 & 6 & & \\
\hline Primary Trauma-Related Diagnosis & & & & & $\chi^{2}=8.860$ & $p=0.065$ \\
\hline PTSD without dissociation, No. (\%) & $16(22.9 \%)$ & $4(12.5 \%)$ & $8(25.0 \%)$ & $4(66.7 \%)$ & $\chi^{2}=8.561$ & $p=0.014$ \\
\hline PTSD Dissociative Subtype, No. (\%) & $17(24.3 \%)$ & $8(25.0 \%)$ & $8(25.0 \%)$ & $1(16.7 \%)$ & $\chi^{2}=0.207$ & $p=0.902$ \\
\hline PTSD + Major Dissociative Disorders & $37(52.9 \%)$ & $20(62.5 \%)$ & $16(50.0 \%)$ & $1(16.7 \%)$ & $\chi^{2}=4.453$ & $p=0.108$ \\
\hline PTSD + DDNOS, No. (\%) & $3(4.3 \%)$ & $0(0.0 \%)$ & $3(9.4 \%)$ & $0(0.0 \%)$ & - & - \\
\hline PTSD + DID, No. (\%) & $34(48.6 \%)$ & $20(62.5 \%)$ & $13(40.6 \%)$ & $1(16.7 \%)$ & - & - \\
\hline \multicolumn{7}{|l|}{ Co-occurring Disorders } \\
\hline Current Major Depressive Disorder & $5(7.1 \%)$ & $3(9.4 \%)$ & $1(3.1 \%)$ & $1(16.7 \%)$ & $\chi^{2}=1.840$ & $p=0.399$ \\
\hline Borderline Personality Disorder & $15(21.4 \%)$ & $6(18.8 \%)$ & $7(21.9 \%)$ & $2(33.3 \%)$ & $\chi^{2}=0.645$ & $p=0.724$ \\
\hline $\mathrm{Age}^{1}$, median (range), y & $31(18-62)$ & $31.5(18-61)$ & $30(18-60)$ & $32(21-62)$ & $\chi^{2}=0.665$ & $p=0.717$ \\
\hline$I Q$, mean $\pm S D^{2}$ & $118.3 \pm 8.6$ & $118.0 \pm 8.4$ & $119.0 \pm 8.7$ & $116.7 \pm 9.9$ & $F=0.201$ & $p=0.819$ \\
\hline Parental Education, No. $(\%)^{3}$ & $35(51.5 \%)$ & $16(51.6 \%)$ & $16(51.6 \%)$ & $3(50.0 \%)$ & $\chi^{2}=0.006$ & $p=0.997$ \\
\hline $\begin{array}{l}\text { Childhood Trauma Questionnaire (CTQ) }{ }^{1,4} \text {, } \\
\text { median (range) }\end{array}$ & $79(38-119)^{*}$ & $86(27-119)^{\star}$ & $75(38-113)$ & $62.5(52-79)$ & $\chi^{2}=3.875$ & $p=0.144$ \\
\hline Emotional Abuse & $18(6-25)$ & $18(5-25)$ & $18(8-25)$ & $17(11-19)$ & $\chi^{2}=1.568$ & $p=0.457$ \\
\hline Physical Abuse & $10(5-25)$ & $12(5-23)$ & $10(5-25)$ & $8(5-19)$ & $\chi^{2}=1.184$ & $p=0.553$ \\
\hline Sexual Abuse & $21(5-25)^{\star}$ & $21(5-25)^{\star},+$ & $17(5-25)$ & $10(5-22)^{\dagger}$ & $\chi^{2}=6.218$ & $p=0.045$ \\
\hline Emotional Neglect & $18(5-25)$ & $19(7-25)$ & $17(5-25)$ & $14.5(7-24)$ & $\chi^{2}=1.034$ & $p=0.596$ \\
\hline Physical Neglect & $12(5-21)$ & $12(5-21)$ & $12(5-21)$ & $10(6-13)$ & $\chi^{2}=1.002$ & $p=0.606$ \\
\hline $\begin{array}{l}\text { MID Severe Dissociation Score, mean } \pm \\
\text { SD }\end{array}$ & $89.3 \pm 41.3$ & $99.6 \pm 43.8^{\dagger}$ & $85.2 \pm 38.0$ & $56.0 \pm 24.2^{\dagger}$ & $F=3.315$ & $p=0.042$ \\
\hline $\begin{array}{l}\text { PTSD Checklist for DSM-5 (PCL-5) Score, } \\
\text { mean } \pm \text { SD }\end{array}$ & $52.3 \pm 13.6$ & $50.0 \pm 16.1$ & $55.2 \pm 9.1$ & $49.0 \pm 18.4$ & $F=1.355$ & $p=0.265$ \\
\hline $\begin{array}{l}\text { Beck Depression Inventory (BDI), mean } \pm \\
\text { SD }\end{array}$ & $29.0 \pm 10.8$ & $32.7 \pm 11.5$ & $27.9 \pm 10.9$ & $25.8 \pm 6.8$ & $F=1.886$ & $p=0.160$ \\
\hline \multicolumn{7}{|l|}{ Medication $^{5}$} \\
\hline Antipsychotics, No. (\%) & $30(47.6 \%)$ & $14(43.8 \%)$ & $11(34.4 \%)$ & $5(83.3 \%)$ & $\chi^{2}=3.853$ & $p=0.146$ \\
\hline Antidepressants, No. (\%) & $46(73.0 \%)$ & $19(59.4 \%)$ & $21(65.6 \%)$ & $6(100.0 \%)$ & $\chi^{2}=3.101$ & $p=0.212$ \\
\hline Mood Stabilizers, No. (\%) & $25(39.7 \%)$ & $12(37.5 \%)$ & $10(31.3 \%)$ & $3(50.0 \%)$ & $\chi^{2}=0.486$ & $p=0.784$ \\
\hline Sedative-Hypnotics, No. (\%) & $33(52.4 \%)$ & $15(46.9 \%)$ & $15(46.9 \%)$ & 3 (50.0\%) & $\chi^{2}=0.035$ & $p=0.983$ \\
\hline Race & & & & & $\chi^{2}=8.344$ & $p=0.401$ \\
\hline White, No. (\%) & $61(87.1 \%)$ & $30(93.8 \%)$ & $25(78.1 \%)$ & $6(100 \%)$ & - & - \\
\hline Black, No. (\%) & $3(4.3 \%)$ & $1(3.1 \%)$ & $2(6.3 \%)$ & $0(0 \%)$ & - & - \\
\hline Asian, No. (\%) & $4(5.7 \%)$ & $0(0 \%)$ & $4(12.5 \%)$ & $0(0 \%)$ & - & - \\
\hline American Indian, No. (\%) & $1(1.4 \%)$ & $0(0 \%)$ & $1(3.1 \%)$ & $0(0 \%)$ & - & - \\
\hline Other, No. (\%) & $1(1.4 \%)$ & $1(3.1 \%)$ & $0(0 \%)$ & $0(0 \%)$ & - & - \\
\hline Ethnicity & & & & & $\chi^{2}=3.591$ & $p=0.464$ \\
\hline Hispanic, No. (\%) & $2(2.9 \%)$ & $0(0 \%)$ & $2(6.2 \%)$ & $0(0 \%)$ & - & - \\
\hline Non-Hispanic, No. (\%) & 67 (95.7\%) & 31 (96.9\%) & $30(93.8 \%)$ & $6(100 \%)$ & - & - \\
\hline Prefer not to answer, No. (\%) & $1(1.4 \%)$ & $1(3.1 \%)$ & $0(0 \%)$ & $0(0 \%)$ & - & - \\
\hline
\end{tabular}

${ }^{1}$ Age and CTQ scores were not normally distributed, thus the Kruskal-Wallis test was conducted. ${ }^{2}$ Eight participants are missing WASI IQ scores (4 unequivocal VH+; 4 ambiguous VH+). ${ }^{3}$ At least one parent with a 4-year college degree; two participants are missing information on parental education level (1 unequivocal VH+; 1 ambiguous VH+). ${ }^{4}$ Two participants are

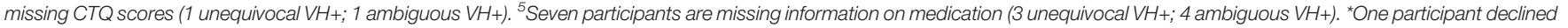

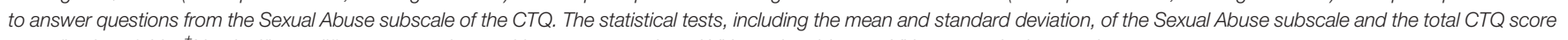
are reflective of this. ${ }^{\dagger}$ No significant difference was detected between unequivocal $\mathrm{VH}+$ and ambiguous $\mathrm{VH}+$ groups in the post hoc test.

Statistics in which at least one of the three groups is significantly different $(p<0.05)$ are shown in bold.

diagnoses, we performed a separate post-hoc analysis for each PTSD subgroup (i.e., PTSD alone, PTSD dissociative subtype, and PTSD plus major dissociative disorder). We found a statistically significant association between $\mathrm{VH}$ group and primary diagnosis for the subgroup of 16 patients who had
PTSD alone $(p=0.014)$, with the majority of these patients (66.7\%) unequivocally reporting no $\mathrm{VH}$, and fewer of these individuals having either unequivocal (12.5\%) or ambiguous $\mathrm{VH}$ (25.0\%). There were no associations between $\mathrm{VH}$ group and primary diagnosis for the subgroups of patients with PTSD 
dissociative subtype $(p=0.902)$ or PTSD with a major dissociative disorder $(p=0.108)$. In spite of the significant association between the non- $\mathrm{VH}$ group and the diagnosis of PTSD without dissociation, as mentioned, the three VH groups did not differ with respect to severity of PTSD symptoms, as measured by the PCL-5.

Consistent with the above, ANOVA showed that at least one of the three VH groups was statistically significantly different with respect to the severe dissociation score for the full MID $\left(F_{2,67}=\right.$ 3.315, $p=0.042$ ). Post-hoc pair-wise analysis showed that the statistically significant difference was driven by the difference between the unequivocal $\mathrm{VH}$ and unequivocal non- $\mathrm{VH}$ groups ( $p$ $=0.044$ ). The unequivocal non- $\mathrm{VH}$ group had a significantly lower MID severe dissociation score compared to the unequivocal $\mathrm{VH}$ group. The ambiguous $\mathrm{VH}$ group was comparable with both the unequivocal $\mathrm{VH}$ group $(p=0.325)$ and the unequivocal non- $\mathrm{VH}$ group $(p=0.236)$ in severe dissociation score.

Furthermore, though the three groups reported similar overall severity of childhood trauma as measured by the CTQ total score, and comparable CTQ subscale scores for emotional abuse, physical abuse, emotional neglect, and physical neglect in childhood (Table 3 ), the groups were significantly different in severity of childhood sexual abuse $(p=0.045)$. Again, post-hoc pair-wise comparisons showed that the group-wise difference in CTQ childhood sexual abuse was due to a difference between the unequivocal $\mathrm{VH}$ and unequivocal non- $\mathrm{VH}$ groups $(p=0.045$, Bonferroni-adjusted for three tests), with the unequivocal non$\mathrm{VH}$ group showing significantly lower mean childhood sexual abuse score. Importantly, there were no statistically significant differences in childhood sexual abuse between the two $\mathrm{VH}$ groups ( $p=0.510$, Bonferroni-adjusted).

With respect to specific types of trauma exposures, the three $\mathrm{VH}$ groups did not significantly differ on exposure to the various types of child abuse or overall lifetime trauma assessed by the TEI (Supplementary Tables 1 and 4). The groups also showed no differences with respect to who perpetrated the abuse experienced during childhood (Supplementary Table 3). However, there was a significant difference in the age at which patients first experienced physical abuse, with both the unequivocal and ambiguous $\mathrm{VH}$ groups reporting earlier first ages of physical abuse compared to the non- $\mathrm{VH}$ group. No differences were seen in the first age at which verbal and sexual abuse began (Supplementary Table 2).

\section{Rates of Voice Hearing in PTSD: SCID vs. MID}

Thirty-two (45.7\%) of the 70 total patients included in the analyses met threshold for SCID item B16 (Auditory Hallucinations). When we calculated the $\mathrm{VH}$ rate using the MID, i.e., examining the proportion of patients meeting clinically significant criteria for at least one MID VH item, the rate went up to $91.4 \%$ (64 of 70 patients) (Figure 2).

\section{ROC Curves}

We conducted ROC analyses to assess the ability of the MID VH items to predict an endorsement of auditory hallucinations as measured by SCID B16. We calculated the ROC curves using two slightly different summary measures for MID VH. When we investigated the MID VH dissociation score against B16, the AUC was 0.741 (95\% CI 0.627-0.856, $p=0.001$ ) (Figure 3A). When we investigated the MID frequency of pathological $\mathrm{VH}$ against B16, the AUC was 0.748 (95\% CI 0.633-0.862, $p=3.87 \mathrm{x}$ $10^{-4}$ ) (Figure 3B).

\section{Phenomenological Comparison of the Unequivocal vs. Ambiguous Voice Hearing Groups}

The two $\mathrm{VH}$ groups showed systematic differences in $\mathrm{VH}$ phenomenology. When we examined between-group differences in dissociation score for each $\mathrm{VH}$ scale, we found the unequivocal $\mathrm{VH}$ group to have higher scores for Schneiderian voices, persecutory voices, and child voices relative to the ambiguous $\mathrm{VH}$ group. However, only the between-group difference in child voices survived Bonferroni-correction for multiple comparisons (Figure 4). Post-hoc analysis of specific items in the child voices scale revealed that a significantly greater proportion of individuals in the unequivocal vs. ambiguous VH groups endorsed Q97 ("hearing a lot of noise or yelling in your head") (71.9\% vs. $34.4 \%$; $p=0.009$, Bonferroni-corrected) and Q118 ("hearing voices crying in your head") (62.5\% vs. $21.9 \%, p=0.003$, Bonferroni-corrected). There was no between-group difference in Q6 ("hearing the voice of a child in your head") ( $56.3 \%$ vs. $34.4 \%$; $p=0.237$, Bonferroni-corrected), which is the other item in the child voices scale.

When we examined between-group differences in mean frequency for each $\mathrm{VH}$ scale, we found the unequivocal $\mathrm{VH}$ group to have higher mean frequencies for Schneiderian voices, persecutory voices, and child voices. Only the differences in Schneiderian voices and child voices survived Bonferroni correction (Figure 5). When we performed post-hoc analyses of

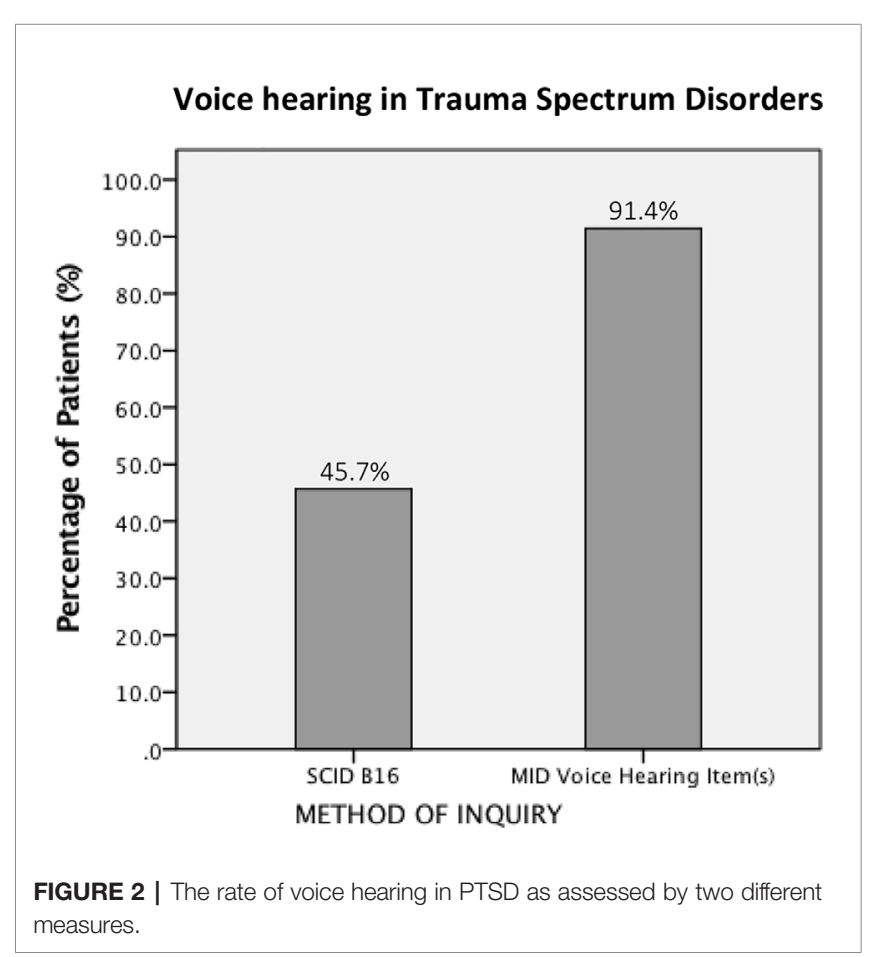



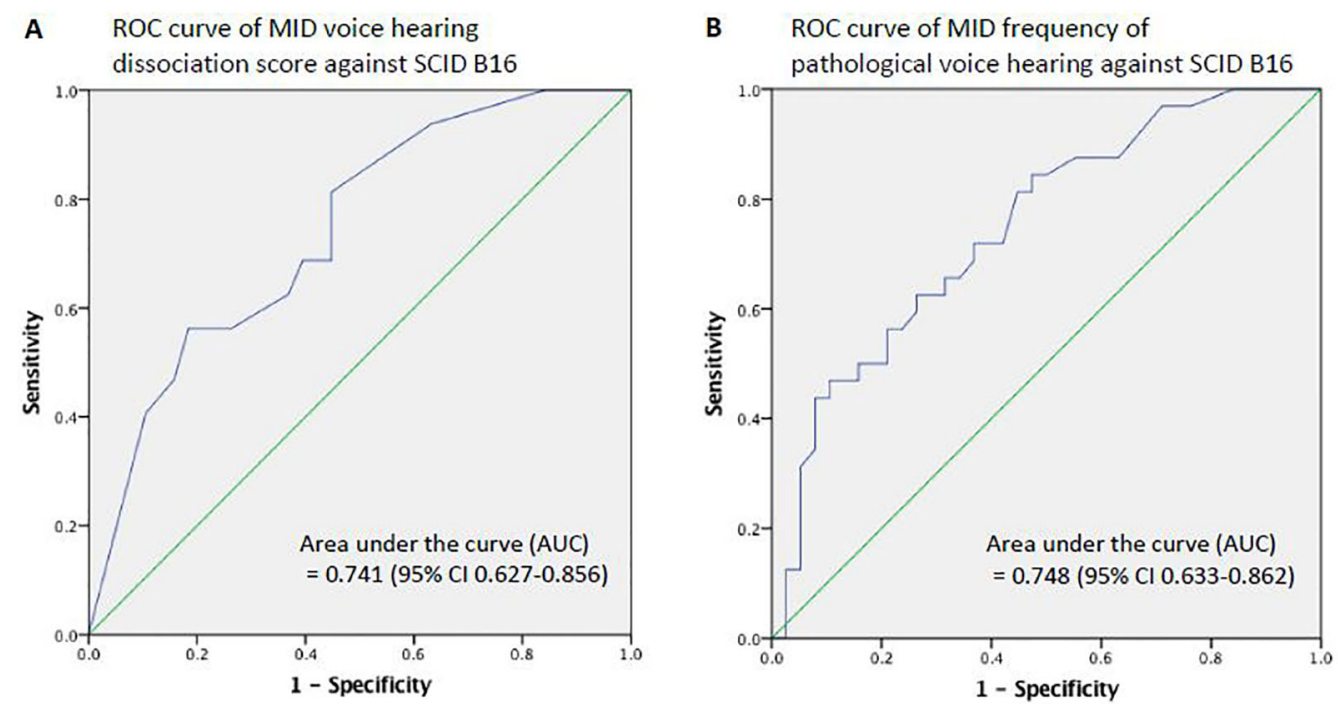

FIGURE 3 | Receiver operating characteristics (ROC) curves. (A) The MID voice hearing dissociation score reflects the total number of pathological VH items in the MID experienced by each individual (possible range 0-12). (B) MID voice hearing frequency is the sum of severity scores of individual items across the full range of the Likert scale (possible range 0-112). While B16 and MID VH scores have greater than chance agreement, the strength of agreement is only moderate, suggesting that $\mathrm{B} 16$ and MID VH items measure related, but not identical, constructs.

individual items in these two scales, we found that the unequivocal VH group, relative to the ambiguous VH group, reported higher frequencies for items Q42 ("hearing a voice in your head that tries to tell you what to do") (median 4 vs. $0, p=0.027$, Bonferronicorrected), Q97 (5 vs. 0, $p=0.018$, Bonferroni-corrected), and Q118 (3.5 vs. $0, p=0.009$, Bonferroni-corrected). We found no statistically significant differences between unequivocal and ambiguous VH groups in Schneiderian VH items Q30 (6 vs. 0, $p$ $=0.054), \mathrm{Q} 140$ (6.5 vs. $1, p=0.684), \mathrm{Q} 171$ ( 1 vs. $0, p=1)$, Q199 (4 vs. $0, p=1$ ), Q207 (7 vs. 2, $p=0.612$ ) (NB: all p-values are Bonferronicorrected for 9 comparisons). Again, among the child voices items, there was no between-group difference in item Q6 (3.5 vs. 0, $p=$ 0.234, Bonferroni-corrected).

\section{DISCUSSION}

In this study, we estimated the proportion of patients with $\mathrm{VH}$ in a sample of female patients with PTSD and dissociative disorders related to a history of childhood abuse and neglect. We estimated this using two different measures-item B16 in the SCID-IV-TR, the gold-standard instrument to diagnose DSM-IV-TR schizophrenia and related psychotic disorders, and the Multidimensional Inventory of Dissociation (MID), a comprehensive self-report questionnaire that assesses the phenomenological domains for pathological dissociation. We found that $\mathrm{VH}$ is common, regardless of method of inquiry. However, the rate of $\mathrm{VH}$ depends on how you ask. In a single patient sample, we found the proportion of individuals with $\mathrm{VH}$ to be $45.7 \%$ when using SCID item B16 and $91.4 \%$ when measured with the MID. ROC analyses showed that while
SCID B16 and the MID VH items have greater than chance agreement, the strength of the agreement is only moderate, suggesting that B16 and the MID VH items measure related, but not identical, constructs. Finally, we found that there were systematic differences between unequivocal voice hearers (individuals who endorsed both B16 and MID VH items) and ambiguous voice hearers (those who endorsed MID VH items but not B16) in VH phenomenology.

\section{It Matters How You Ask}

One of the main findings from our study is that how someone is asked about $\mathrm{VH}$ matters. The proportion of $\mathrm{VH}$ individuals detected by the MID was double that identified by the SCID. This is a striking discrepancy in $\mathrm{VH}$ rate given that both estimates arise from the same patient sample. The discrepancy can be explained by considering differences in the way that the MID and SCID B16 ascertain VH. First, the MID assesses VH through the lens of primarily dissociative experiences, while B16, which is embedded within the psychotic disorders module of the SCID, is immediately preceded by a series of questions about delusions and followed by questions about hallucinations in other sensory modalities. These other psychotic symptoms may resonate less well with patients with trauma-related and other non-psychotic disorders and make it less likely for a patient to endorse B16 even if, in a strict sense, the individual has heard "things that other people couldn't, such as noises or the voices of people whispering or talking." Both patients and interviewers may add layers of meaning and interpretation to B16 based on the context in which B16 is asked, and patients may harbor concerns that they will be diagnosed with a psychotic disorder if they answer affirmatively to any item in the psychotic disorders module. For example, some 
A

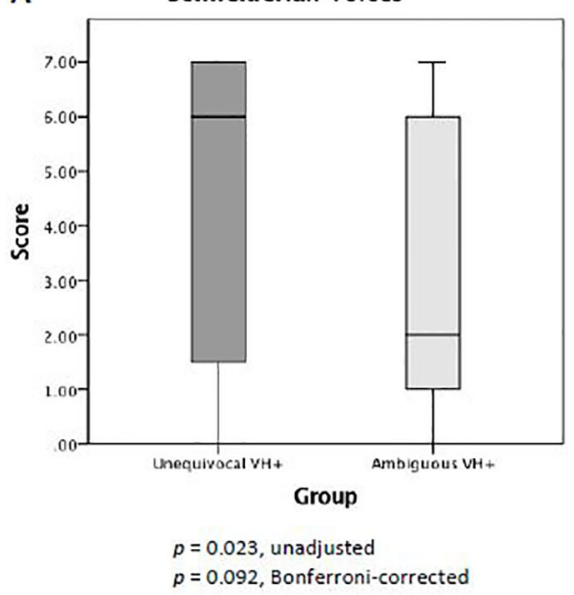

C

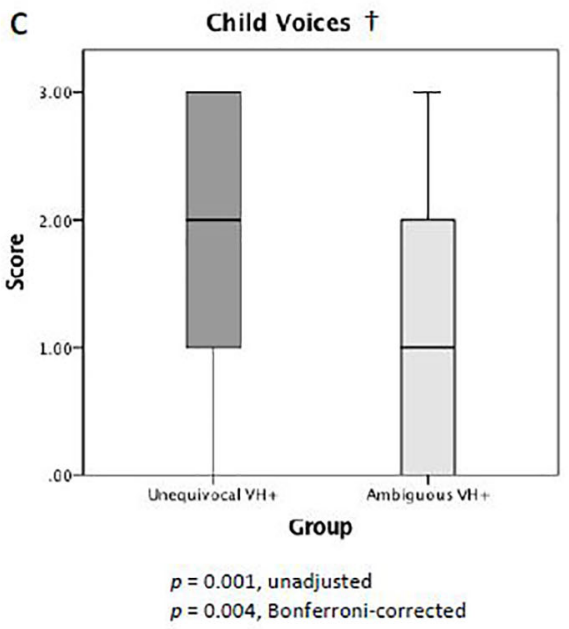

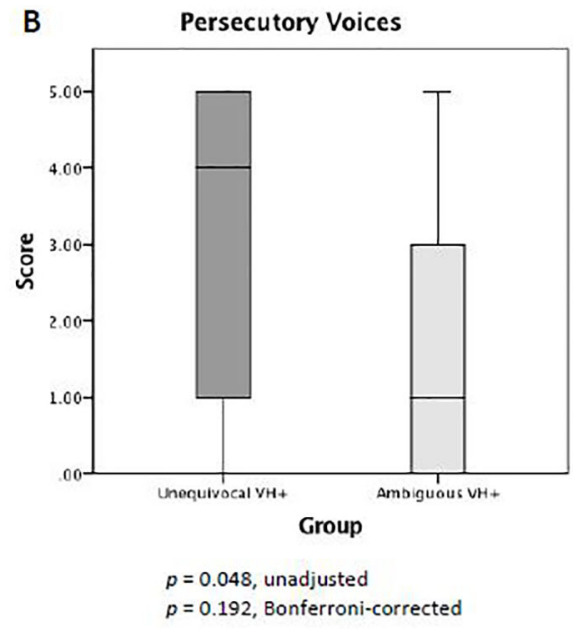

D

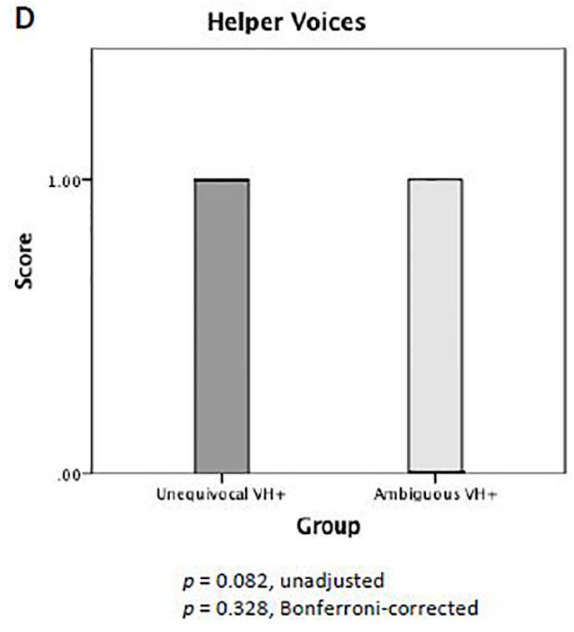

FIGURE 4 | Scores for pathological voice hearing. Compared to the ambiguous VH group, the unequivocal VH group showed higher MID VH dissociation scores for Schneiderian voices (A), persecutory voices (B), and child voices (C). †Only the between-group difference in child voices (C) survived multiple comparisons correction.

participants in this study asked if B16 includes flashbacks. From DSM-III (76) through DSM-IV-TR (105), because of the special significance given to voices commenting or voices conversing in diagnosing schizophrenia, having either of those $\mathrm{VH}$ experiences alone without other core (criterion A) symptoms could, in fact, lead to a diagnosis of schizophrenia. According to studies that have examined pathways to care in patients with dissociative disorders, between $15.6 \%$ to $49 \%$ of individuals received a diagnosis of schizophrenia prior to being diagnosed with DID $(8,9,51,54,55,59,72)$. More appropriately, the DSM-5, hearing voices commenting or conversing in isolation is no longer sufficient to meet diagnostic criteria for schizophrenia (33).

Second, the MID asks about VH experiences with thirteen different questions, and thus is more likely to capture at least one $\mathrm{VH}$ experience compared to the single auditory hallucination item in the SCID. While items B17 (voices conversing) and B18 (voices commenting) in the SCID also inquire about auditory hallucinations, those items are assessed only if the patient initially responds affirmatively to the B16 gatekeeper item. As such, the SCID provides only one opportunity to screen for $\mathrm{VH}$.

Third, the MID utilizes a $0-10$ Likert scale format and offers a wider spectrum of responses, with finer gradations based on severity/frequency, while the SCID B16 forces ratings into more limited and categorical response options (i.e., absent, subthreshold, or present, with a fourth option if there is insufficient information). Even if MID dissociation scores transform frequency ratings into a dichotomous variable based on a clinical cut-off, respondents are not aware of this when they respond, and cut-off scores vary from item to item.

Fourth, the MID is a self-report questionnaire, while the SCID is a semi-structured interview. While semi-structured interviews administered by experienced clinicians are considered the goldstandard method of conducting a psychiatric evaluation, a selfadministration format may allow individuals to disclose about $\mathrm{VH}$ and other experiences that are considered pathological with potentially less stigma, shame, and judgment. Self- 

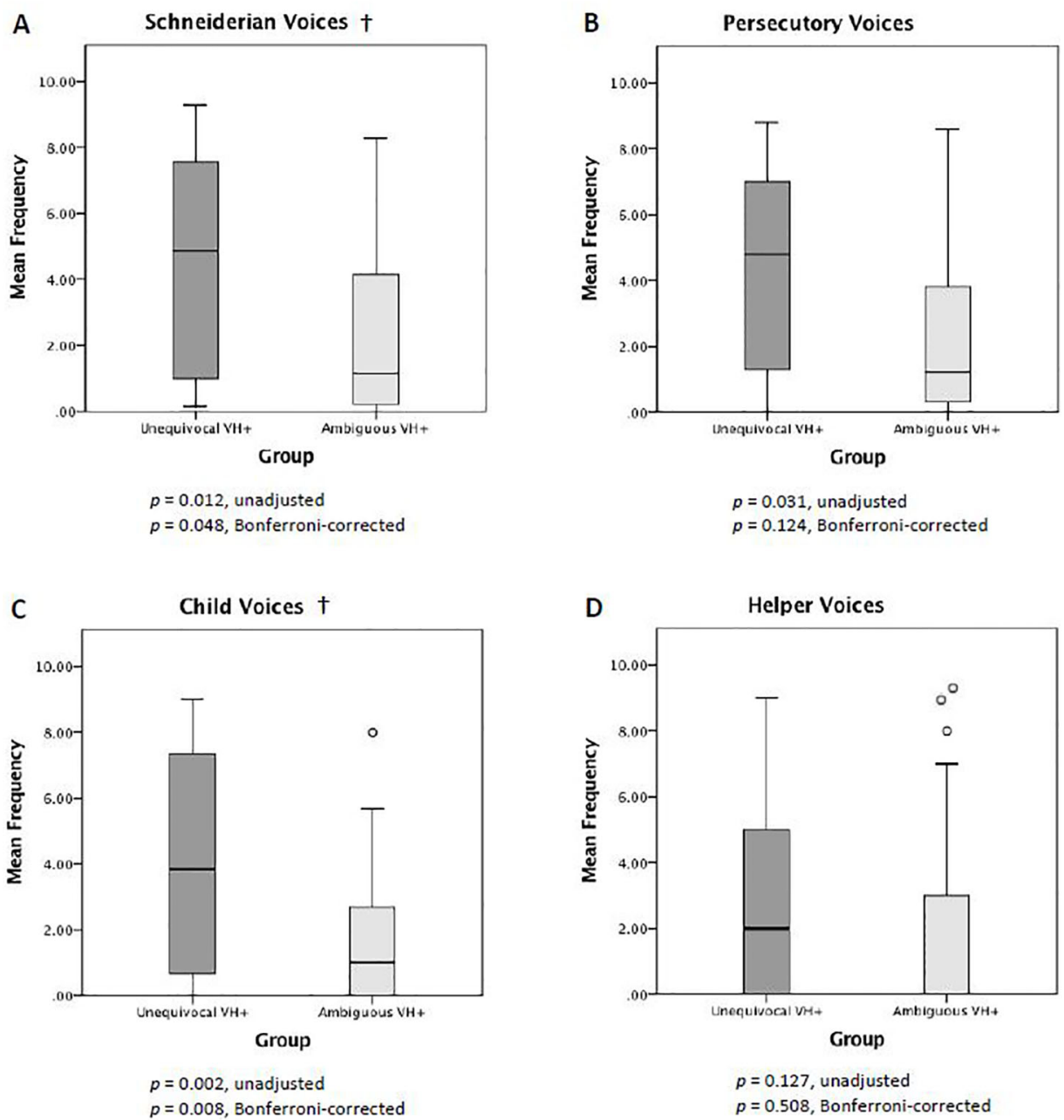

FIGURE 5 | Mean frequency of pathological voice hearing. Compared to the ambiguous VH group, the unequivocal VH group showed higher mean MID VH frequency scores for Schneiderian voices $\mathbf{( A )}$, persecutory voices (B), and child voices (C). †The between-group differences in Schneiderian voices (A) and child voices (C) survived multiple comparisons correction.

administration forms would thus be expected to increase reporting compared to a clinician administered interview, and this phenomenon has been observed in the PTSD literature [e.g., meta-analysis by (106)]. On the other hand, self-reporting could also lead to an effect in the opposite direction. A recent study (48) found that the same question about VH (DES-II item 27) resulted in endorsement by $32.5 \%$ with self-report vs. $45 \%$ during semi-structured interview, suggesting that self-report could also lead to underreporting of $\mathrm{VH}$ (or over-reporting in semi-structured interview).

Fifth, all the VH items in the MID-except for the psychosis screener, MID Q98-asks about VH “in your head.” It is unclear what impact the qualification of "in your head" might have on how individuals respond to the MID items. Whether $\mathrm{VH}$ location is a clinically significant phenomenological feature has been debated for decades. Some studies have reported that a greater proportion of trauma than schizophrenia patients experience internal voices $(44,93)$, but other studies that have directly compared trauma and schizophrenia spectrum patients on this feature have reported no difference $(6,12,92,107)$. Furthermore, many studies have shown that VH location does not separate cleanly by diagnosis; internal and external voices appear to be prevalent in both trauma-related and schizophrenia spectrum patients, and many individuals experience both $(12,44$, $92,93,107)$. A review that found that the proportion of people with exclusively external $\mathrm{VH}$ and, conversely, exclusively internal $\mathrm{VH}$ are similar in schizophrenia, dissociative disorders, other psychiatric patients, and non-patients (94). Though voices heard inside the head have occasionally been referred to in the literature as "pseudohallucinations," the term - which has been used variably and inconsistently to refer not only to internal voices, but also perceptual disorders lacking sensory vividness, hallucinations with intact reality-testing and insight, egosyntonic versus alien voices, voluntary or involuntary voices, 
and/or isolated hallucinations without other psychopathology $(108,109)$ - has been argued to lack construct validity (109). In the case of MID VH items, "in your head" could refer to a voice that is heard internally rather than externally, or it could reflect that the voice hearer has insight that the experience is a product of the voice hearer's mind. How critical the phrase "in your head" is in capturing the $\mathrm{VH}$ experience in this patient sample is unknown, since there are no MID VH items that are phrased comparably but without the words "in your head". Nevertheless, "in your head" may be associated with less stigma and greater acceptability, and thereby increase rates of affirmative responses to MID VH. Unlike the MID, item B16 in the SCID does not make any specifications about whether voices and other sounds must be heard outside the head for the experience to meet threshold, though this does not rule out the possibility of interviewer bias when rating B16.

Lastly, the MID and SCID B16 differ with respect to the time frame that is assessed. The MID instructs individuals to indicate "how often do you have the following experiences...," in the present tense, suggesting a focus on current or recent experiences. The SCID, on the other hand, assesses whether the individual has "ever" in his or her lifetime had VH or other auditory hallucinatory experiences. Assessing for "ever" experience of $\mathrm{VH}$ would be expected to have the effect of inflating the proportion of patients endorsing B16. However, in our sample, asking about lifetime $\mathrm{VH}$ with B16 did not outweigh other factors, as a substantially greater proportion of patients endorsed MID VH relative to $\mathrm{B} 16$.

Beyond considerations about differences in the format and contextual characteristics of the instruments themselves, the data additionally provide insights into differences between the measures' ability to detect potentially substantive clinical differences. We found systematic differences between individuals who endorse both measures (unequivocal voice hearers) and those who endorse VH only on the MID (ambiguous voice hearers). The unequivocal $\mathrm{VH}$ group reported significantly higher scores and mean frequencies on the child voices scale, and higher mean frequencies on the Schneiderian voices scale, compared to the ambiguous $\mathrm{VH}$ group. When we examined the individual items within the child voices and Schneiderian voices scales, hearing voices with the phenomenological qualities of crying, commanding, or voices that sound like a lot of noise or yelling in the head most distinguished unequivocal from ambiguous voice hearers. These differences in the two VH groups do not appear to be due merely to differences in clinical severity, as there were no statistically significant differences between the unequivocal and ambiguous VH groups on demographic or clinical characteristics, including on measures of childhood sexual abuse, depression severity, PTSD symptom severity, or severity of dissociation.

\section{Psychosis, Dissociation, and/or Other?}

In this paper, we analyzed $\mathrm{VH}$ using two measures intended to assess different constructs: SCID B16, which measures schizophrenia-related auditory hallucinations, and the MID, which measures pathological dissociation. Thus, we interpret our data primarily through these lenses, of psychosis and dissociation, respectively.

The German psychiatrist Kurt Schneider described specific forms of $\mathrm{VH}$ - consisting of two or more voices conversing with one another, or voices commenting on one's thoughts, beliefs, and actions-as "first rank," or pathognomonic of schizophrenia (110). Reflecting this historical conceptualization, schizophrenia and related disorders are the only major psychiatric disorder category in the current Diagnostic and Statistical Manual of Mental Disorders (DSM-5) (33) - other than substance related disorders, neurocognitive disorders (e.g., Lewy body disease), or delirium - that explicitly includes hallucinations in the diagnostic criteria. Despite the fact that $\mathrm{VH}$ is not uncommon in trauma spectrum disorders, neither hallucinations nor $\mathrm{VH}$ are included in the diagnostic criteria for PTSD or DID. In the DSM, there is no mention of $\mathrm{VH}$ in the criteria or text description of PTSD. For DID, while the DSM-5 text description of diagnostic features mentions that individuals with DID can experience "perceptions of voices (e.g., a child's voice; crying; the voice of a spiritual being)," and that in some cases, "voices are experienced as multiple, perplexing, independent thought streams over which the individual experiences no control" (p. 293) (33), VH and other passive-influence experiences are not part of the DSM DID diagnostic criteria (10). Thus, when clinicians encounter a patient who reports hearing voices in the absence of substances and non-psychiatric medical or neurological conditions, they are often faced with the dilemma of whether to diagnose that individual with a psychotic disorder, even when such a diagnosis may not otherwise fit with the overall clinical presentation. $\mathrm{VH}$ frequently leads to a diagnosis of primary psychotic disorder when, in fact, underlying traumarelated disorders may sometimes be primary.

The results of our ROC curve analyses suggest that $\mathrm{VH}$ measured by the MID and auditory hallucinations measured SCID B16 are related but not identical constructs. While the exact pathophysiology underlying $\mathrm{VH}$ remains unknown, different meanings, mechanisms, and conceptual frameworks have been proposed for $\mathrm{VH}$ in schizophrenia spectrum vs. TSD. Auditory hallucinations in schizophrenia and related psychotic disorders are commonly conceptualized as a problem of over-perceptualization [e.g., (111-115)] as well of impaired reality monitoring and misattribution [e.g., $(116,117)]$, i.e., inner speech and thoughts that are internally generated are perceived as originating outside the self. Importantly, evidence suggests that $\mathrm{VH}$ may be a consequence of faulty circuitry, or dysconnectivity, in the brain (118). Studies implicate disruptions both within and between brain areas involved in auditory perception, speech and language, top-down inhibition, memory encoding and/or storage, self-monitoring, and error prediction, among other brain functions (112, 115, 119-124).

In the context of TSD, VH is more often conceptualized within a psychological framework, i.e., as a psychological reaction to traumatic or emotionally overwhelming events to which the individual has previously been exposed (125). Voices commenting and voices conversing-along with other forms of 
"made" actions, feelings, and impulses-are considered to reflect dissociative intrusions, which are intrusions into consciousness by a self-state that is partially dissociated (10). When chronically exposed to traumatic events, integrative capacities become compromised and traumatic experiences are not appropriately encoded and consolidated in autobiographical memory (126). The personality becomes divided, with traumatic memories less accessible to autobiographical narrative memory (126). VH, while distinct from flashbacks, is one form in which such dissociated traumatic content can be reactivated into conscious awareness $(2,125)$. These conceptual frameworks, relating to psychotic vs. dissociative $\mathrm{VH}$, highlight different mechanisms, but the models are not necessarily mutually exclusive, and $\mathrm{VH}$ in schizophrenia and TSD may share areas of overlap.

The MID is designed to detect pathological dissociative experiences and $91.4 \%$ of patients met criteria for at least one MID VH item. Thus, it seems clear that VH has some element of dissociation for the majority of individuals in our sample. Our finding that women with PTSD who endorsed both B16 and MID $\mathrm{VH}$ items had significantly greater and more severe experiences on the child voices scale compared to those who endorsed $\mathrm{VH}$ only on the MID can be interpreted within the context of dissociation. Child voices in individuals with trauma-related disorders who report histories of childhood abuse and neglect are conceptualized as compartmentalized intrusion symptoms, and may represent reexperience of past traumatic events (127). In DID, such intrusions often are personified as "child voices" and are relationally significant. Child voices may represent cognitions, affects, or conflicts held in relationship to significant attachment figures from childhood (128). While child voices are considered in this context within a dissociation model of $\mathrm{VH}$, it is possible that the dissociative experience of hearing child voices, especially child voices crying or yelling, is experienced as more severe, intrusive, and alien than other dissociative experiences, and that this is what leads to a greater likelihood for an individual to meet threshold for B16. On the other hand, we also found that individuals who endorsed both B16 and MID VH items also reported greater severity of Schneiderian voices. Schneiderian symptoms, which are symptoms relating to a breakdown of self-other boundaries, have traditionally been considered to belong in the realm of psychosis. Thus, it is also possible to interpret $\mathrm{VH}$ experiences in the unequivocal $\mathrm{VH}$ group in the context of psychosis.

Unfortunately, our data are limited in the ability to determine whether the $\mathrm{VH}$ experiences in the subset of individuals who endorse SCID B16 in addition to MID also have a psychotic component similar to auditory hallucinations in schizophrenia spectrum disorders. In our ROC curve analyses, we set SCID B16 as the reference measure, as $\mathrm{VH}$ is usually considered a hallucinatory experience and the SCID psychotic disorders module is the gold standard for identifying psychotic symptoms in the context of diagnosing psychotic disorders. By doing so, we make the assumption in our ROC analysis that B16 represents "true" or a more accurate measure of VH. However, given the relatively limited research in this area, we do not know if B16 functions the same in individuals with trauma spectrum disorders as it does in psychotic disorders. In our trauma spectrum sample, it is unclear if B16 is actually detecting psychosis, merely a more severe form of dissociation, and/or something else. Accuracy can be defined in terms of both sensitivity (the ability of a test to correctly identify true positives) and specificity (the ability of a test to correctly identify true negatives). As the MID detects more individuals with $\mathrm{VH}$ experiences, it could potentially be argued that the MID is a more sensitive measure. Conversely, if SCID B16 identifies $\mathrm{VH}$ experiences that are more psychotic in nature, then B16 may have greater specificity for a narrower definition of auditory hallucinations.

Future studies should further investigate how MID VH items and SCID B16 relate to one another. We consider possible relationships: 1) $\mathrm{VH}$ in trauma-related disorders could be a 'phenocopy' of $\mathrm{VH}$ in psychotic disorders. In the field of genetics, the term phenocopy refers to a phenotype that falsely mimics the true phenotype (129). Phenocopies have a different cause than the condition that they mimic. Using phenocopies in genetics as a metaphor, perhaps $\mathrm{VH}$ in trauma-related and schizophrenia spectrum disorders arise from fundamentally different pathogenesis and are only superficially similar (qualitatively or even just semantically). 2) It is possible that psychosis and dissociation share fundamental similarities, and that $\mathrm{VH}$ in trauma spectrum and schizophrenia spectrum disorders lie on a common psychosis-dissociation continuum. McCarthy-Jones and Longden (125) have reported, though through indirect comparisons, that the phenomenology of $\mathrm{VH}$ in PTSD and schizophrenia is highly similar, and that differences, if they exist, are quantitative rather than qualitative. 3) Lastly, dissociation and psychosis may be phenomena that are distinct but associated with one another. With respect to this latter hypothesis, several researchers have proposed that dissociation operates as a mediator in the relationship between trauma and VH (130-133). An association between dissociation and VH has been described in PTSD $(45,46)$ and DID $(92,93,134)$, as well as in psychosis $(131,132,135-144)$. It has been theorized that dissociative detachment, induced by trauma, deprives the individual of both external and internal "anchors," including the "sense of being connected to one's own body, a sense of self or identity, and one's own actions," thus leading to impaired reality testing, confusion, disorganization, and disorientation (145). It is possible that $\mathrm{VH}$ as measured by the MID, which captures $\mathrm{VH}$ from a dissociative framework, may be a mediator between childhood trauma and more psychotic forms of $\mathrm{VH}$.

Despite the significant overlap in symptomatology between trauma spectrum and schizophrenia spectrum disorders, research efforts in the respective fields of trauma-related disorders and schizophrenia have mostly occurred along separate paths (146). Most schizophrenia studies do not measure trauma-related or dissociative symptoms, and studies investigating PTSD and/or dissociative disorders infrequently administer psychosis scales. The current study applies measures of dissociation and psychosis only to individuals with traumarelated disorders. To better answer the question of whether $\mathrm{VH}$ in trauma-related disorders is psychotic or even contains components that are psychotic and not just dissociative, studies that directly compare trauma spectrum and 
schizophrenia spectrum patients using the same "grid" of instruments-including both well-validated dissociation measures and well-validated psychosis measures-are critically needed. Future investigations that employ neuroimaging, electrophysiology, and/or other methods to directly compare the neural mechanisms underlying $\mathrm{VH}$ in trauma-related and schizophrenia spectrum disorders may also shed more light into the degree to which $\mathrm{VH}$ experiences in these conditions are fundamentally similar or merely phenocopies of one another.

\section{Current Findings in Relation to Previous Studies}

Given the discrepancy of our two estimates of $\mathrm{VH}$ rate which are derived from a single patient sample, it is no surprise that such wide variability of estimates exists among previous studies, which collectively applied numerous different methods of defining and measuring VH (Table 1A, B). Many of the studies that used standardized dissociation instruments to estimate $\mathrm{VH}$ show that the majority of individuals with trauma-related disorders experience VH. For example, Brewin and Patel (45) used the Dissociative Experiences Scale (DES) (63) to assess VH among military veterans with PTSD and found a VH rate of 59.6\%. Two independent research groups, Ross and colleagues (56) and Sar and colleagues (8), administered the Dissociative Disorders Interview Schedule (DDIS) $(70,71)$ and found similarly high rates of individuals who heard voices talking $(87.2 \%$ and $94.3 \%$, respectively) despite sampling dissociative disorders patients from different countries (USA, Turkey). Boon and Draijer (59) used the Structured Clinical Interview for Dissociative Disorders (SCID-D) (89) to estimate VH in dissociative identity disorder patients from The Netherlands and found that $94.2 \%$ reported voices commenting and $90.1 \%$ voices arguing. Similarly, Dell (10) administered the MID (the dissociation instrument used in this study) to DID patients and found that 95\% reported voices commenting and $89 \%$ voices arguing. These estimates, especially the latter which are drawn from samples of patients with dissociative disorders, are in line with the $\mathrm{VH}$ rate of $91.4 \%$ that we observed in our sample of women with PTSD, many of whom also have dissociative disorders.

Relative to studies that used dissociation-oriented measures, studies employing psychosis-oriented assessment tools have generally reported lower $\mathrm{VH}$ rates. For example, two studies used the SCID for DSM-III-R (87) to estimate auditory hallucinations in combat veterans with PTSD: David and colleagues (42) reported a rate of $37.7 \%$, and Hamner and colleagues (43) $46.7 \%$. These estimates are highly consistent with the $\mathrm{VH}$ rate of $45.7 \%$ that we found using SCID B16 in this study. Of note, the auditory hallucinations item in the SCID for DSM-III-R (B35) is identical to item B16 in the SCID for DSM-IV-TR used in the current study. Butler and colleagues (41), using the Scale for the Assessment of Positive Symptoms (SAPS) (85), estimated that $25 \%$ of Vietnam veterans with PTSD related to verifiable combat experience had hallucinations (this study estimated hallucinations in any sensory modality, not auditory hallucinations or $\mathrm{VH}$, per se). Anketell and colleagues (46), using the Positive and Negative Syndrome Scale (PANSS)
(64) in combination with specific inquiries about "noises and voices inside their head that others can't hear", estimated that $\mathrm{VH}$ occurred in $50 \%$ of chronic PTSD patients. While studies that use psychosis instruments to ascertain $\mathrm{VH}$ in trauma-related disorders have generally reported lower rates, it should also be noted that most of the studies that use psychosis-oriented assessment tools were conducted in PTSD patients, while nearly all dissociative disorders studies used instruments from the dissociation literature.

The variability in the literature is not only due to differences in how $\mathrm{VH}$ is measured but is also related to differences in patient samples. VH has been reported in 13.9-59.6\% of patients with PTSD related to military combat $(7,39-43,45,46)$, and in $5-85 \%$ of civilian samples with PTSD $(44-46,48)$. The rate of VH among refugees with PTSD was $27.1 \%$ (47) (Table 1A). Several dissociative disorders studies clearly described patient samples in which the majority had been exposed to childhood trauma, and these studies reported VH rates of $30 \%-100 \%$ (Table 1B).

To our knowledge, ours is the first study to examine $\mathrm{VH}$ in patients with PTSD related to childhood abuse, many of whom also had high levels of dissociative symptoms. Our study sample was generally characterized by a high overall trauma load, including verbal, physical, and sexual abuse afflicted by multiple perpetrators, starting very early in life, and that was experienced recurrently over extended periods of time. Consistent with these features, the vast majority reported severe histories of childhood abuse and neglect across all domains assessed in the CTQ. Further, patients in our sample had high levels of dissociation. For example, the average MID severe dissociation score of the unequivocal voice hearers was 99.6 and that of the ambiguous voice hearers was 85.2. These scores indicate that on average the groups endorsed over half (59\% and 51\%, respectively) of the pathological dissociation items on the MID to a clinically significant level.

Studies conducted in samples consisting primarily of adult women with DSM-IV or DSM-IV-TR DID-which are the most clinically and demographically comparable to our samplefound rates of $\mathrm{VH}$ that are strikingly consistent with our rate of $91.4 \%$ as measured by the MID. For example, Sar and colleagues (8) reported a VH rate of $94.3 \%$, Middleton and Butler (9) reported 98\%, and Dell (10) 95\%. Though Putnam and colleagues (51) appear to have studied a comparable sample of mostly women with dissociative disorders, they reported a much lower $\mathrm{VH}$ rate, of $30 \%$. This rate appears to be an outlier among the dissociative disorders studies reviewed. Notably, the Putnam study did not involve any direct participation by patients, but rather utilized a mail-in survey to clinicians, which may be subject to greater clinician bias. Our estimates also contrast starkly with the VH rate of only $5 \%$ which Clifford and colleagues (48) recently reported in a civilian sample with PTSD related to physical and sexual abuse. However, in contrast to our sample, the sample in the Clifford study (48) was characterized by markedly less dissociative symptoms, as evidenced by a mean \pm SD DES-II score of $26.8 \pm 19.0$, which falls below the average DES score of 48 for DID in research and even below the average DES score of 31 for PTSD (67). The 
associations observed in our sample between non-VH and trauma-related diagnosis of PTSD alone (without dissociation) and with lower MID dissociation scores suggest that $\mathrm{VH}$ may be closely linked to the experience of dissociative symptoms. Furthermore, while the Clifford study is similar to ours in that they studied a civilian sample with physical and sexual abuse, less than half of their sample had experienced such trauma during childhood. The lower rate of childhood trauma in the Clifford study contrasts with our study, which required participants to have a history of childhood abuse to be study eligible. Lastly, there may be some sex differences in the rate of $\mathrm{VH}$ among trauma-related disorders $(34,50)$, and the gender distribution of the Clifford sample was not specified.

\section{Limitations}

Our findings should be considered in the context of several limitations. First, as we have discussed, our study is limited in its ability to resolve whether the unequivocal voice hearers in our sample (i.e., those who endorsed SCID B16 in addition to MID $\mathrm{VH}$ items) experience $\mathrm{VH}$ that is not just dissociative but also psychotic in nature. The SCID only screens for lifetime presence or absence of auditory hallucinatory experiences. We did not administer other well-validated psychosis measures, such as the SAPS or PANSS, which are designed to measure differences in symptom severity. Nor did we administer more multidimensional hallucination scales, such as the Psychotic Symptom Rating Scale (PSYRATS) (147) or the Auditory Hallucination Rating Scale (AHRS) (148), which provide more phenomenologically rich information about auditory hallucinations. More importantly, we investigated $\mathrm{VH}$ only in trauma spectrum patients. There is a critical need to directly compare trauma and schizophrenia spectrum patients with respect to $\mathrm{VH}$ epidemiology, phenomenology, and underlying neurobiology to determine whether the transdiagnostic experience of $\mathrm{VH}$ is fundamentally similar or different in these two categories of psychiatric illness.

Second, there are limitations related to the representativeness of our sample: (a) This study entailed secondary analysis of existing data, and the data were not collected from all patients consecutively admitted to or evaluated at our trauma specialty service. Thus, the total sample in our denominator may not be fully representative of individuals with TSD, let alone individuals with TSD at McLean Hospital. On the other hand, as the aims of the original study did not relate to $\mathrm{VH}$, there was no active bias to deliberately seek out voice hearing individuals for recruitment. (b) Another major limitation is that our sample of 70 patients is small, and the proportions we observed in our study are unlikely to reflect the true prevalence of $\mathrm{VH}$, which would be best estimated by largescale, population-based epidemiological studies. On the other hand, a sample size of 70 is relatively large in the scope of the existing literature on dissociative phenomenology, especially the literature on VH in TSD as can be seen in Table 1A, B. (c) We studied a fairly narrow subgroup of TSD — namely, female PTSD patients with childhood trauma histories and severe dissociative symptoms who were receiving care at a specialized PTSD treatment center. Thus, our findings may not be broadly generalizable. On the other hand, most existing studies of VH in PTSD were conducted in primarily male combat veterans. Women, especially those with histories of childhood abuse, are relatively underrepresented in PTSD research, and our study helps to fill a gap in the literature about the rate and phenomenology of VH in women with PTSD and dissociative psychopathology related to childhood trauma. Another important point is that while our small and somewhat unique sample might limit the generalizability of our findings, issues relating to the representativeness of our sample do not take away from one of our main findings that even within a single sample, two different instruments lead to two very different estimates of VH. d) We combined PTSD patients with and without dissociative symptoms into a single TSD group. However, our results (Table 3 ) suggest that these groups may differ in the distribution of $\mathrm{VH}$ experiences. The rates of $\mathrm{VH}$ observed in our sample may better approximate the prevalence of $\mathrm{VH}$ in individuals who suffer a constellation of both PTSD and dissociative symptoms, and likely overestimate the rate of $\mathrm{VH}$ in PTSD samples with minimal dissociative psychopathology.

Third, the frequency and experience of $\mathrm{VH}$ within an individual can change over time, and our data, which are cross-sectional, are limited in the ability to provide insights about the evolution or stability of $\mathrm{VH}$ over time. More longitudinal studies are needed to address this issue. Fourth, a related consideration is that clinical acuity could potentially impact the frequency and severity of $\mathrm{VH}$, and our sample consisted of patients at various levels of care, including outpatient, partial hospital, residential, and inpatient settings. However, the unequivocal and ambiguous $\mathrm{VH}$ groups did not statistically significantly differ on measures of PTSD, dissociation, or depressive symptom severity.

Fifth, all participants were medicated at the time of study participation, and it is unclear what effect medications, especially antipsychotic medications, had on the experience of $\mathrm{VH}$ in this sample. Two small double-blind, randomized placebo-controlled trials provide preliminary evidence that the antipsychotic risperidone may be effective in women with chronic noncombat related PTSD $(149,150)$. However, other studies have not demonstrated sufficient evidence of benefit of antipsychotic medications in the treatment of PTSD (151) or DID (152), and, to our knowledge, there have been no studies systematically investigating the effect of antipsychotic medications specifically on $\mathrm{VH}$ in trauma-related disorders. Even if antipsychotic medications did have the effect of reducing $\mathrm{VH}$, there was no statistically significant difference in the proportion of patients in our sample who were on antipsychotic medications across the three groups. The unequivocal non-VH (B16-/MID-) group did contain a higher proportion of patients on antipsychotic medications $(83.3 \%)$ relative to the other two groups $(43.8 \%$ in the unequivocal $\mathrm{VH}$ group, $34.4 \%$ in the ambiguous $\mathrm{VH}$ group), even if this difference was not statistically significant. Thus, some could question if the absence of $\mathrm{VH}$ in this group could be related to the greater proportion of patients being treated with antipsychotic medications in this group. For example, it is conceivable that antipsychotics could have been prescribed because of VH. However, this scenario is unlikely since the SCID item B16 asks about ever/lifetime history of $\mathrm{VH}$ or 
auditory hallucinations (not just current or recent experiences), and this item was coded as negative for all patients in this group. More importantly, the two VH groups for whom we make phenomenological comparisons were more comparable with respect to antipsychotic exposure. Therefore, the phenomenological differences we found between the two $\mathrm{VH}$ groups do not appear to be due to any systematic differences in antipsychotic exposure between them.

Finally, it is worth acknowledging that any attempt to study and phenomenologically classify a subjective experience, including $\mathrm{VH}$, is inevitably fraught with semantic challenges. Language is a necessary vehicle for communication but can be limited in its ability to accurately reflect the nuances of an individual's internal experience. People may not always have the words to describe the subtleties and complexities of subjective self-experiences, which unlike other things in everyday experience have no physical characteristics (153). This may be especially true when it comes to more unusual internal experiences, which may have an ineffable and prereflective quality $(154,155)$. Moreover, depending on an individual's life experience and background, the same words can have different meanings for different people. This is true not only for patients, but also for clinicians and researchers in different fields who may have differing theoretical frameworks and expertise (153). Neurobiological approaches to investigating similarities and differences between "psychotic" vs. "dissociative" vs. other types of $\mathrm{VH}$ may help to move past some of these semantic barriers.

\section{Conclusions}

The experience of $\mathrm{VH}$ is given little diagnostic or treatment consideration in trauma spectrum disorders. There is little to no mention of $\mathrm{VH}$ in previous or current versions of the DSM sections on PTSD and dissociative disorders. However, our estimates of VH rate (45.7\% using SCID B16, and 91.4\% using MID VH items) are in line with previous studies that used comparable instruments and comparable patient samples, and suggest that $\mathrm{VH}$ is more ubiquitous in trauma-related disorders than traditionally recognized. We found high rates of $\mathrm{VH}$ in our sample of women with trauma spectrum disorders, irrespective of method of inquiry. However, the MID-based rate of $91.4 \%$, in particular, suggests that $\mathrm{VH}$ may not merely be a secondary feature of trauma-related disorders, but rather reflective of some core process or phenomenon more fundamental in posttraumatic and especially dissociative conditions. It remains to be resolved whether $\mathrm{VH}$ in trauma-related disorders has components that are psychotic in addition to dissociative in a subset of patients. Nonetheless, our results add to the growing scientific evidence that hearing voiceswhich is an experience typically considered psychotic or psychoticlike-is not equivalent to having a psychotic disorder. In fact, it is increasingly recognized that there is a continuum of $\mathrm{VH}$ that transcends even the boundaries of mental illness, extending to individuals with $\mathrm{VH}$ in the general population $(18,156)$. Increased recognition among both patients and clinicians that $\mathrm{VH}$ is not uncommon in trauma-related disorders can reduce potential misdiagnosis of PTSD and dissociative disorder as cases of schizophrenia, which in turn has significant treatment implications.
A key finding from our study is that it matters how you ask about VH. Using only instruments that are narrowly designed to detect $\mathrm{VH}$ and other psychotic symptoms in schizophrenia and related psychotic disorders may potentially have greater specificity for a certain form of $\mathrm{VH}$, but underestimate a broader range of $\mathrm{VH}$ experiences. Until we have better understanding about the underlying nature and pathogenesis of different types of $\mathrm{VH}$, instruments that assess $\mathrm{VH}$ more agnostically, apart from psychotic disorders, and that capture the multidimensional nature of the experience should be considered to improve identification of $\mathrm{VH}$ experiences, especially among patients with non-psychotic disorders.

\section{DATA AVAILABILITY STATEMENT}

The datasets generated for this study are available on request to the corresponding author.

\section{ETHICS STATEMENT}

The study was approved by the Partners Healthcare Institutional Review Board. All participants gave written informed consent in accordance with the Declaration of Helsinki.

\section{AUTHOR CONTRIBUTIONS}

AS analyzed the data, interpreted the results, and drafted the manuscript. $\mathrm{MH}$ analyzed the data and contributed to results interpretation and manuscript drafting. MK, JW, and LL collected the data and contributed to interpretation of the results and manuscript drafting. SW contributed to data collection and interpretation. MR contributed to data analysis and interpretation of the results. DO and KR contributed to interpretation of the results and manuscript drafting. All authors approved the final manuscript version.

\section{FUNDING}

This research was supported by NIH K23MH100611 and the McLean Hospital Pope-Hintz Fellowship to AS, and NIH R21MH112986 to MK and KR.

\section{ACKNOWLEDGMENTS}

We are grateful to the patients who participated in this research.

\section{SUPPLEMENTARY MATERIAL}

The Supplementary Material for this article can be found online at: https://www.frontiersin.org/articles/10.3389/fpsyt.2019. 01011/full\#supplementary-material 


\section{REFERENCES}

1. Pierre JM. Hallucinations in nonpsychotic disorders: toward a differential diagnosis of "hearing voices". Harv Rev Psychiatry (2010) 18:22-35. doi: $10.3109 / 10673220903523706$

2. Longden E, Madill A, Waterman MG. Dissociation, trauma, and the role of lived experience: toward a new conceptualization of voice hearing. Psychol Bull (2012) 138:28-76. doi: 10.1037/a0025995

3. Waters F, Blom JD, Jardri R, Hugdahl K, Sommer IEC. Auditory hallucinations, not necessarily a hallmark of psychotic disorder. Psychol Med (2018) 48(4):529-36. doi: 10.1017/S0033291717002203

4. Baethge C, Baldessarini RJ, Freudenthal K, Streeruwitz A, Bauer M, Bschor T. Hallucinations in bipolar disorder: characteristics and comparison to unipolar depression and schizophrenia. Bipolar Disord (2005) 7:136-45. doi: 10.1111/ j.1399-5618.2004.00175.x

5. Shinn AK, Pfaff D, Young S, Lewandowski KE, Cohen BM, Ongur D. Auditory hallucinations in a cross-diagnostic sample of psychotic disorder patients: a descriptive, cross-sectional study. Compr Psychiatry (2012) 53:71826. doi: 10.1016/j.comppsych.2011.11.003

6. Jessop M, Scott J, Nurcombe B. Hallucinations in adolescent inpatients with post-traumatic stress disorder and schizophrenia: similarities and differences. Australas Psychiatry (2008) 16:268-72. doi: 10.1080/10398560801982580

7. Crompton L, Lahav Y, Solomon Z. Auditory hallucinations and PTSD in exPOWS. J Trauma Dissociation (2017) 18:663-78. doi: 10.1080/ 15299732.2016.1267682

8. Sar V, Yargic LI, Tutkun H. Structured interview data on 35 cases of dissociative identity disorder in Turkey. Am J Psychiatry (1996) 153:132933. doi: 10.1176/ajp.153.10.1329

9. Middleton W, Butler J. Dissociative identity disorder: an Australian series. Aust N Z J Psychiatry (1998) 32:794-804. doi: 10.3109/00048679809073868

10. Dell PF. A new model of dissociative identity disorder. Psychiatr Clin North Am (2006b) 291-26:vii. doi: 10.1016/j.psc.2005.10.013

11. Yee L, Korner AJ, McSwiggan S, Meares RA, Stevenson J. Persistent hallucinosis in borderline personality disorder. Compr Psychiatry (2005) 46:147-54. doi: 10.1016/j.comppsych.2004.07.032

12. Slotema CW, Daalman K, Blom JD, Diederen KM, Hoek HW, Sommer IE. Auditory verbal hallucinations in patients with borderline personality disorder are similar to those in schizophrenia. Psychol Med (2012) 42 (9):1873-8. doi: 10.1016/S0920-9964(12)71022-8

13. Serino A, Heydrich L, Kurian M, Spinelli L, Seeck M, Blanke O. Auditory verbal hallucinations of epileptic origin. Epilepsy Behav (2014) 31:181-6. doi: 10.1016/j.yebeh.2013.12.014

14. Tsunoda N, Hashimoto M, Ishikawa T, Fukuhara R, Yuki S, Tanaka H, et al. Clinical Features of Auditory Hallucinations in Patients With Dementia With Lewy Bodies: a Soundtrack of Visual Hallucinations. J Clin Psychiatry (2018) 79(3):e1-6. doi: 10.4088/JCP.17m11623

15. Lee AH, Weintraub D. Psychosis in Parkinson's disease without dementia: common and comorbid with other non-motor symptoms. Mov Disord (2012) 27:858-63. doi: 10.1002/mds.25003

16. Bentall RP, Slade PD. Reliability of a scale measuring disposition towards hallucinations: a brief report. Pers Individ Dif (1985) 6:527-9. doi: 10.1016/ 0191-8869(85)90151-5

17. Romme MA, Escher AD. Hearing voices. Schizophr Bull (1989) 15:209-16. doi: 10.1093/schbul/15.2.209

18. Tien AY. Distributions of hallucinations in the population. Soc Psychiatry Psychiatr Epidemiol (1991) 26:287-92. doi: 10.1007/BF00789221

19. van Os J, Hanssen M, Bijl RV, Ravelli A. Strauss (1969) revisited: a psychosis continuum in the general population? Schizophr Res (2000) 45:11-20. doi: 10.1016/S0920-9964(99)00224-8

20. Johns LC, Hemsley D, Kuipers E. A comparison of auditory hallucinations in a psychiatric and non-psychiatric group. Br J Clin Psychol (2002) 41:81-6. doi: $10.1348 / 014466502163813$

21. Dhossche D, Ferdinand R, van der Ende J, Hofstra MB, Verhulst F. Diagnostic outcome of self-reported hallucinations in a community sample of adolescents. Psychol Med (2002) 32:619-27. doi: 10.1017/ S003329170200555X

22. Kilpatrick DG, Resnick HS, Milanak ME, Miller MW, Keyes KM, Friedman MJ. National estimates of exposure to traumatic events and PTSD prevalence using DSM-IV and DSM-5 criteria. J Trauma Stress (2013) 26:537-47. doi: $10.1002 /$ jts. 21848

23. Kessler RC, McLaughlin KA, Green JG, Gruber MJ, Sampson NA, zasLAVSKY AM, et al. Childhood adversities and adult psychopathology in the WHO World Mental Health Surveys. Br J Psychiatry (2010) 197:37885. doi: 10.1192/bjp.bp.110.080499

24. Read J, van Os J, Morrison AP, ROSS CA. Childhood trauma, psychosis and schizophrenia: a literature review with theoretical and clinical implications. Acta Psychiatr Scand (2005) 112:330-50. doi: 10.1111/j.16000447.2005.00634.x

25. Varese F, Smeets F, Drukker M, Lieverse R, Lataster T, Viechtbauer W, et al. Childhood adversities increase the risk of psychosis: a meta-analysis of patient-control, prospective- and cross-sectional cohort studies. Schizophr Bull (2012b) 38:661-71. doi: 10.1093/schbul/sbs050

26. Spauwen J, Krabbendam L, Lieb R, Wittchen HU, van Os J. Impact of psychological trauma on the development of psychotic symptoms: relationship with psychosis proneness. Br J Psychiatry (2006) 188:527-33. doi: 10.1192/bjp.bp.105.011346

27. Shevlin M, Dorahy MJ, Adamson G. Trauma and psychosis: an analysis of the National Comorbidity Survey. Am J Psychiatry (2007b) 164:166-9. doi: 10.1176/ajp.2007.164.1.166

28. Shevlin M, Houston JE, Dorahy MJ, Adamson G. Cumulative traumas and psychosis: an analysis of the national comorbidity survey and the British Psychiatric Morbidity Survey. Schizophr Bull (2008) 34:193-9. doi: 10.1093/ schbul/sbm069

29. Arseneault L, Cannon M, Fisher HL, Polanczyk G, Moffitt TE, Caspi A. Childhood trauma and children's emerging psychotic symptoms: A genetically sensitive longitudinal cohort study. Am J Psychiatry (2011) 168:65-72. doi: 10.1176/appi.ajp.2010.10040567

30. Whitfield CL, Dube SR, Felitti VJ, Anda RF. Adverse childhood experiences and hallucinations. Child Abuse Negl (2005) 29:797-810. doi: 10.1016/ j.chiabu.2005.01.004

31. Shevlin M, Dorahy M, Adamson G. Childhood traumas and hallucinations: an analysis of the National Comorbidity Survey. J Psychiatr Res (2007a) 41:222-8. doi: 10.1016/j.jpsychires.2006.03.004

32. Bentall RP, Wickham S, Shevlin M, Varese F. Do specific early-life adversities lead to specific symptoms of psychosis? A study from the 2007 the Adult Psychiatric Morbidity Survey. Schizophr Bull (2012) 38:734-40. doi: $10.1093 /$ schbul/sbs049

33. APA. Diagnostic and Statistical Manual of Mental Disorders, 5th Edition. Washington, DC: American Psychiatric Press (2013).

34. Loewenstein RJ, Putnam FW. The clinical phenomenology of males with MPD: a report of 21 cases. Dissociation (1990) 3:135-43.

35. Kluft RP, Schultz R. Multiple personality disorder in adolescence. Adolesc Psychiatry (1993) 19:259-79.

36. Loewenstein RJ, Putnam FW. Dissociative Disorders. In: Sadock BJ, Sadock VA, editors. Kaplan \& Sadocks Comprehensive Textbook of Psychiatry, Eighth Edition ed.. Lippincott Williams \& Wilkins: Philadelphia, PA (2005).

37. Dalenberg CJ, Brand BL, Gleaves DH, Dorahy MJ, Loewenstein RJ, Cardena E, et al. Evaluation of the evidence for the trauma and fantasy models of dissociation. Psychol Bull (2012) 138:550-88. doi: 10.1037/a0027447

38. Dorahy MJ, Brand BL, Sar V, Kruger C, Stavropoulos P, Martinez-Taboas A, et al. Dissociative identity disorder: An empirical overview. Aust N Z J Psychiatry (2014) 48:402-17. doi: 10.1177/0004867414527523

39. Mueser KT, Butler RW. Auditory hallucinations in combat-related chronic posttraumatic stress disorder. Am J Psychiatry (1987) 144:299-302. doi: 10.1176/ajp.144.3.299

40. Wilcox J, Briones D, SUESS L. Auditory hallucinations, posttraumatic stress disorder, and ethnicity. Compr Psychiatry (1991) 32:320-3. doi: 10.1016/ 0010-440X(91)90080-V

41. Butler RW, Mueser KT, Sprock J, Braff DL. Positive symptoms of psychosis in posttraumatic stress disorder. Biol Psychiatry (1996) 39:839-44. doi: 10.1016/0006-3223(95)00314-2

42. David D, Kutcher GS, Jackson EI, Mellman TA. Psychotic symptoms in combat-related posttraumatic stress disorder. J Clin Psychiatry (1999) 60:2932. doi: 10.4088/JCP.v60n0106

43. Hamner MB, Frueh BC, Ulmer HG, Arana GW. Psychotic features and illness severity in combat veterans with chronic posttraumatic stress 
disorder. Biol Psychiatry (1999) 45:846-52. doi: 10.1016/S0006-3223(98) $00301-1$

44. Scott JG, Nurcombe B, Sheridan J, McFarland M. Hallucinations in adolescents with post-traumatic stress disorder and psychotic disorder. Australas Psychiatry (2007) 15:44-8. doi: 10.1080/10398560601083084

45. Brewin CR, Patel T. Auditory pseudohallucinations in United Kingdom war veterans and civilians with posttraumatic stress disorder. J Clin Psychiatry (2010) 71:419-25. doi: 10.4088/JCP.09m05469blu

46. Anketell C, Dorahy MJ, Shannon M, Elder R, Hamilton G, Corry M, et al. An exploratory analysis of voice hearing in chronic PTSD: potential associated mechanisms. J Trauma Dissociation (2010) 11:93-107. doi: 10.1080/ 15299730903143600

47. Nygaard M, Sonne C, Carlsson J. Secondary psychotic features in refugees diagnosed with post-traumatic stress disorder: a retrospective cohort study. BMC Psychiatry (2017) 17:5. doi: 10.1186/s12888-016-1166-1

48. Clifford G, Dalgleish T, Hitchcock C. Prevalence of auditory pseudohallucinations in adult survivors of physical and sexual trauma with chronic post-traumatic stress disorder (PTSD). Behav Res Ther (2018) 111:113-8. doi: 10.1016/j.brat.2018.10.015

49. Bliss EL. Multiple personalities. A report of 14 cases with implications for Schizophrenia and hysteria. Arch Gen Psychiatry (1980) 37:1388-97. doi: 10.1001/archpsyc. 1980.01780250074009

50. Bliss EL. A symptom profile of patients with multiple personalities, including MMPI results. J Nerv Ment Dis (1984) 172:197-202. doi: 10.1097/00005053198404000-00002

51. Putnam FW, Guroff JJ, Silberman EK, Barban L, Post RM. The clinical phenomenology of multiple personality disorder: review of 100 recent cases. J Clin Psychiatry (1986) 47:285-93.

52. Coons PM, Milstein V. Psychosexual disturbances in multiple personality: characteristics, etiology, and treatment. J Clin Psychiatry (1986) 47:106-10. doi: 10.1037/e609912012-020

53. Kluft RP. First-rank symptoms as a diagnostic clue to multiple personality disorder. Am J Psychiatry (1987) 144:293-8. doi: 10.1176/ajp.144.3.293

54. Coons PM, Bowman ES, Milstein V. Multiple personality disorder. A clinical investigation of 50 cases. J Nerv Ment Dis (1988) 176:519-27. doi: 10.1097/ 00005053-198809000-00001

55. Ross CA, Norton GR, Wozney K. Multiple personality disorder: an analysis of 236 cases. Can J Psychiatry (1989b) 34:413-8. doi: 10.1177/ 070674378903400509

56. Ross CA, Miller SD, Reagor P, Bjornson L, Fraser GA, Anderson G. Structured interview data on 102 cases of multiple personality disorder from four centers. Am J Psychiatry (1990c) 147:596-601. doi: 10.1176/ ajp.147.5.596

57. Dell PF, Eisenhower JW. Adolescent multiple personality disorder: a preliminary study of eleven cases. J Am Acad Child Adolesc Psychiatry (1990) 29:359-66. doi: 10.1097/00004583-199005000-00005

58. Hornstein NL, Putnam FW. Clinical phenomenology of child and adolescent dissociative disorders. J Am Acad Child Adolesc Psychiatry (1992) 31:107785. doi: 10.1097/00004583-199211000-00013

59. Boon S, Draijer N. Multiple personality disorder in The Netherlands: a clinical investigation of 71 patients. Am J Psychiatry (1993) 150:489-94. doi: 10.1176/ajp.150.3.489

60. Coons PM. Clinical Phenomenology of 25 Children and Adolescents with Dissociative Disorders. Child Adolesc Psychiatr Clinics North America (1996) .5:pp. doi: 10.1016/S1056-4993(18)30371-7

61. Keane TM, Malloy PF, fairbank JA. Empirical development of an MMPI subscale for the assessment of combat-related posttraumatic stress disorder. J Consult Clin Psychol (1984) 52:888-91. doi: 10.1037/0022-006X.52.5.888

62. Kaufman J, Birmaher B, Brent D, Rao U, Flynn C, Moreci P, et al. Schedule for Affective Disorders and Schizophrenia for School-Age Children-Present and Lifetime Version (K-SADS-PL): initial reliability and validity data. J Am Acad Child Adolesc Psychiatry (1997) 36:980-8. doi: 10.1097/00004583199707000-00021

63. Bernstein EM, Putnam FW. Development, reliability, and validity of a dissociation scale. J Nerv Ment Dis (1986) 174:727-35. doi: 10.1097/ 00005053-198612000-00004
64. Kay SR, Fiszbein A, Opler LA. The positive and negative syndrome scale (PANSS) for schizophrenia. Schizophr Bull (1987) 13:261-76. doi: 10.1093/ schbul/13.2.261

65. Solomon Z, Horesh D, Ein-Dor T, Ohry A. Predictors of PTSD trajectories following captivity: a 35-year longitudinal study. Psychiatry Res (2012) 199:188-94. doi: 10.1016/j.psychres.2012.03.035

66. Derogatis LR. The SCL-90 manual: Scoring, administration and procedures for the SCL-90. Johns Hopkins School of Medicine, Clinical Psychometrics Unit: Baltimore, MD (1977).

67. Carlson EB, Putnam FW. An update on the Dissociative Experiences Scale. Dissociation: Prog In Dissociative Disord (1993) 6:16-27.

68. Mellor CS. First rank symptoms of schizophrenia. I. The frequency in schizophrenics on admission to hospital. II. Differences between individual first rank symptoms. Br J Psychiatry (1970) 117:15-23. doi: $10.1192 / \mathrm{S} 0007125000192116$

69. Carpenter WTJr., Strauss JS, Muleh S. Are there pathognomonic symptoms in schizophrenia? An empiric investigation of Schneider's first-rank symptoms. Arch Gen Psychiatry (1973) 28:847-52. doi: 10.1001/ archpsyc.1973.01750360069010

70. Ross CA, Heber S, Norton GR, Anderson D, Anderson G, Barchet P, et al. The Dissociative Disorders Interview Schedule: A structured interview. Dissociation: Prog Dissociative Disord (1989) 2:169-89.

71. Ross CA, Heber S, Anderson G. The Dissociative Disorders Interview Schedule. Am J Psychiatry (1990a) 147:1698-9. doi: 10.1176/ajp.147.12.1698-b

72. Ross CA, Miller SD, Reagor P, Bjornson L, Fraser GA, Anderson G. Schneiderian symptoms in multiple personality disorder and schizophrenia. Compr Psychiatry (1990b) 31:111-8. doi: 10.1016/0010440X(90)90014-J

73. Overall JE, Gorham DR. The brief psychiatric rating scale (BPRS). Psychol Rep (1962) 10:799-812. doi: 10.2466/pr0.1962.10.3.799

74. Blake DD, Weathers F, Nagy LM, Kaloupek DG, Klauminzer G, Charney DS A clinician rating scale for assessing current and lifetime PTSD: The CAPS1. Behav Ther (1990) 13:187-8.

75. Putnam FW, Helmers K, Trickett PK. Development, reliability, and validity of a child dissociation scale. Child Abuse Negl (1993) 17:731-41. doi: 10.1016/S0145-2134(08)80004-X

76. APA. Diagnostic and Statistical Manual of Mental Disorders, Third Edition. American Psychiatric Press: Washington, D.C. (1980).

77. APA. Diagnostic and Statistical Manual of Mental Disorders, 4th Edition. American Psychiatric Press: Washington, DC (1994).

78. Dell PF. The multidimensional inventory of dissociation (MID): A comprehensive measure of pathological dissociation. J Trauma Dissociation (2006a) 7:77-106. doi: 10.1300/J229v07n02_06

79. Hathaway SR, C. MJ. Manual for the Minnesota Multiphasic Personality Inventory. Minneapolis, MN: University of Minnesota Press (1942).

80. Keane TM, Caddell JM, Taylor KL. Mississippi Scale for Combat-Related Posttraumatic Stress Disorder: three studies in reliability and validity. $J$ Consult Clin Psychol (1988) 56:85-90. doi: 10.1037/0022-006X.56.1.85

81. Foa E. Posttraumatic Stress Diagnostic Scale (PDS) Manual. Minneapolis, MN: National Computer Systems (1995).

82. Foa EB, Riggs DS, Dancu CV, Rothbaum BO. Reliability and validity of a brief instrument for assessing post-traumatic stress disorder. J Traumatic Stress (1993) 6:459-73. doi: 10.1002/jts.2490060405

83. Solomon Z, Benbenishty R, Neria Y, Abramowitz M, Ginzburg K, Ohry A. Assessment of PTSD: validation of the revised PTSD Inventory. Isr J Psychiatry Relat Sci (1993) 30:110-5.

84. Feighner JP, Robins E, Guze SB. Diagnostic criteria for use in psychiatric research. Arch Gen Psychiatry (1972) 26:57-63. doi: 10.1001/ archpsyc.1972.01750190059011

85. Andreasen NC. The Scale for the Assessment of Positive Symptoms (SAPS). Iowa City: Iowa, University of Iowa (1984).

86. Johnson MH, Magaro PA, Stern SL. Use of the SADS-C as a diagnostic and symptom severity measure. J Consult Clin Psychol (1986) 54:546-51. doi: 10.1037/0022-006X.54.4.546

87. Spitzer RL, Williams JB, Gibbon M, First MB. Structured Clinical Interview for DSM-III-R. Arlington, VA, US: American Psychiatric Association (1990). 
88. First MB, Spitzer RL, Gibbon M, Williams JBW. Structured clinical interview for DSM-IV Axis I Disorders. New York: New York State Psychiatric Institute, Biometrics Research (1995). doi: 10.1037/t07827-000

89. Steinberg M, Rounsaville B, Cicchetti DV. The Structured Clinical Interview for DSM-III-R Dissociative Disorders: preliminary report on a new diagnostic instrument. Am J Psychiatry (1990) 147:76-82. doi: 10.1176/ajp.147.1.76

90. Steinberg M. Structured clinical interview for DSM-IV Dissociative Disorders (SCID-D), Revised. Washington, D.C.: American Psychiatric Press (1994).

91. Seedat S, Stein MB, Oosthuizen PP, Emsley RA, Stein DJ. Linking posttraumatic stress disorder and psychosis: a look at epidemiology, phenomenology, and treatment. J Nerv Ment Dis (2003) 191:675-81. doi: 10.1097/01.nmd.0000092177.97317.26

92. Honig A, Romme MA, Ensink BJ, Escher SD, Pennings MH, Devries MW. Auditory hallucinations: a comparison between patients and nonpatients. $J$ Nerv Ment Dis (1998) 186:646-51. doi: 10.1097/00005053-199810000-00009

93. Dorahy MJ, Shannon C, Seagar L, Corr M, Stewart K, Hanna D, et al. Auditory hallucinations in dissociative identity disorder and schizophrenia with and without a childhood trauma history: similarities and differences. $J$ Nerv Ment Dis (2009) 197:892-8. doi: 10.1097/NMD.0b013e3181c299ea

94. Moskowitz A, Corstens D. Auditory hallucinations: psychotic symptom or dissociative experience? J Psychol Trauma (2007) 6:35-63. doi: 10.1300/ J513v06n02_04

95. Weathers FW, Blake DD, Schnurr PP, Kaloupek DG, Marx BP, Keane TM. The Clinician-Administered PTSD Scale for DSM-5 (CAPS-5). National Center for PTSD (2013).

96. First MB, Gibbon M, Spitzer RL, Williams JBW, Benjamin LS. Structured Clinical Interview for DSM-IV Axis II Personality Disorders (SCID-II). Washington, DC: American Psychiatric Press, Inc. (1997).

97. First MB, Spitzer RL, Gibbon M, Williams JBW. Structured Clinical Interview for DSM-IV-TR Axis I Disorders, Research Version, Patient Edition. (SCID-I/P). New York, NY: Biometrics Research, New York State Psychiatric Institute (2002).

98. Dell PF, Lawson D. Empirically delineating the domain of pathological dissociation. In: Dell PF, O'Neil JA, editors. Dissociation and the dissociative disorders: DSM-V and beyond. Routledge, Taylor \& Francis Group: New York, NY (2009). doi: 10.4324/9780203893920

99. Bernstein DP, Fink L. Childhood Trauma Questionnaire: A Retrospective SelfReport Manual. San Antonio, TX: The Psychological Corporation (1998).

100. Weathers FW, Litz BT, Keane TM, Palmieri PA, Marx BP, Schnurr PP. The PTSD Checklist for DSM-5 (PCL-5). National Center for PTSD (2013).

101. Blevins CA, Weathers FW, Davis MT, Witte TK, Domino JL. The Posttraumatic Stress Disorder Checklist for DSM-5 (PCL-5): Development and Initial Psychometric Evaluation. J Trauma Stress (2015) 28:489-98. doi: $10.1002 /$ jts.22059

102. Beck AT, Ward CH, Mendelson M, Mock J, Erbaugh J. An inventory for measuring depression. Arch Gen Psychiatry (1961) 4:561-71. doi: 10.1001/ archpsyc.1961.01710120031004

103. Binder EB, Bradley RG, Liu W, Epstein MP, Deveau TC, Mercer KB, et al. Association of FKBP5 polymorphisms and childhood abuse with risk of posttraumatic stress disorder symptoms in adults. JAMA (2008) 299:1291305. doi: 10.1001/jama.299.11.1291

104. Wechsler D. Wechsler Abbreviated Scale of Intelligence, Second Edition (WASI-II). NCS Pearson: San Antonio, TX (2011). doi: 10.1037/t15171-000

105. APA. Diagnostic and Statistical Manual of Mental Disorders, 4th Edition, Text Revision. Washington, DC: American Psychiatric Press (2000).

106. Edmondson D, Richardson S, Falzon L, Davidson KW, Mills MA, Neria Y. Posttraumatic stress disorder prevalence and risk of recurrence in acute coronary syndrome patients: a meta-analytic review. PloS One (2012) 7: e38915. doi: 10.1371/journal.pone.0038915

107. Kingdon DG, Ashcroft K, Bhandari B, Gleeson S, Warikoo N, Symons M, et al. Schizophrenia and borderline personality disorder: similarities and differences in the experience of auditory hallucinations, paranoia, and childhood trauma. J Nerv Ment Dis (2010) 198:399-403. doi: 10.1097/ NMD.0b013e3181e08c27

108. Berrios GE, Dening TR. Pseudohallucinations: a conceptual history. Psychol Med (1996) 26:753-63. doi: 10.1017/S0033291700037776
109. van der Zwaard R, Polak MA. Pseudohallucinations: a pseudoconcept? A review of the validity of the concept, related to associate symptomatology. Compr Psychiatry (2001) 42:42-50. doi: 10.1053/comp.2001.19752

110. Schneider K. Clinical psychopathology. New York: Grune \& Stratton (1959).

111. Dierks T, Linden DE, Jandl M, Formisano E, Goebel R, Lanfermann H, et al. Activation of Heschl's gyrus during auditory hallucinations. Neuron (1999) 22:615-21. doi: 10.1016/S0896-6273(00)80715-1

112. Hugdahl K. "Hearing voices": auditory hallucinations as failure of top-down control of bottom-up perceptual processes. Scand J Psychol (2009) 50:55360. doi: 10.1111/j.1467-9450.2009.00775.x

113. Northoff G, Qin P. How can the brain's resting state activity generate hallucinations? A 'resting state hypothesis' of auditory verbal hallucinations. Schizophr Res (2011) 127:202-14. doi: 10.1016/ j.schres.2010.11.009

114. Kompus K, Westerhausen R, Hugdahl K. The "paradoxical" engagement of the primary auditory cortex in patients with auditory verbal hallucinations: a meta-analysis of functional neuroimaging studies. Neuropsychologia (2011) 49:3361-9. doi: 10.1016/j.neuropsychologia.2011.08.010

115. Nazimek JM, Hunter MD, Woodruff PW. Auditory hallucinations: expectation-perception model. Med Hypotheses (2012) 78:802-10. doi: 10.1016/j.mehy.2012.03.014

116. Feinberg I. Efference copy and corollary discharge: implications for thinking and its disorders. Schizophr Bull (1978) 4:636-40. doi: 10.1093/schbul/ 4.4.636

117. Ditman T, Kuperberg GR. A source-monitoring account of auditory verbal hallucinations in patients with schizophrenia. Harv Rev Psychiatry (2005) 13:280-99. doi: 10.1080/10673220500326391

118. Stephan KE, Friston KJ, Frith CD. Dysconnection in schizophrenia: from abnormal synaptic plasticity to failures of self-monitoring. Schizophr Bull (2009) 35:509-27. doi: 10.1093/schbul/sbn176

119. Allen P, Laroi F, McGuire PK, Aleman A. The hallucinating brain: a review of structural and functional neuroimaging studies of hallucinations. Neurosci Biobehav Rev (2008) 32:175-91. doi: 10.1016/j.neubiorev.2007.07.012

120. Northoff G. Are Auditory Hallucinations Related to the Brain's Resting State Activity? A 'Neurophenomenal Resting State Hypothesis'. Clin Psychopharmacol Neurosci (2014) 12:189-95. doi: 10.9758/cpn.2014.12.3.189

121. Aleman A, Bocker KB, Hijman R, de Haan EH, Kahn RS. Cognitive basis of hallucinations in schizophrenia: role of top-down information processing. Schizophr Res (2003) 64:175-85. doi: 10.1016/S0920-9964(03)00060-4

122. Curcic-Blake B, Ford JM, Hubl D, Orlov ND, Sommer IE, Waters F, et al. Interaction of language, auditory and memory brain networks in auditory verbal hallucinations. Prog Neurobiol (2017) 148:1-20. doi: 10.1016/ j.pneurobio.2016.11.002

123. Alderson-Day B, McCarthy-Jones S, Fernyhough C. Hearing voices in the resting brain: A review of intrinsic functional connectivity research on auditory verbal hallucinations. Neurosci Biobehav Rev (2015) 55:78-87. doi: 10.1016/j.neubiorev.2015.04.016

124. Alderson-Day B, Diederen K, Fernyhough C, Ford JM, Horga G, Margulies DS, et al. Auditory Hallucinations and the Brain's Resting-State Networks: Findings and Methodological Observations. Schizophr Bull (2016) 42:111023. doi: $10.1093 / \mathrm{schbul} / \mathrm{sbw} 078$

125. McCarthy-Jones S, Longden E. Auditory verbal hallucinations in schizophrenia and post-traumatic stress disorder: common phenomenology, common cause, common interventions? Front Psychol (2015) 6:1071. doi: 10.3389/fpsyg.2015.01071

126. van der Hart O, Nijenhuis ER, Steele K. Dissociation: An insufficiently recognized major feature of complex posttraumatic stress disorder. J Trauma Stress (2005) 18:413-23. doi: 10.1002/jts.20049

127. van der Hart O, Nijenhuis ERS, Steele K. The Haunted Self: Structural Dissociation and the Treatment of Chronic Traumatization. New York, NY: W. W. Norton (2006).

128. Howell EF. Understanding and Treating Dissociative Identity Disorder: A Relational Approach. New York, NY: Routledge (2011). doi: 10.4324/ 9780203888261

129. Lescai F, Franceschi C. The impact of phenocopy on the genetic analysis of complex traits. PloS One (2010) 5:e11876. doi: 10.1371/journal.pone.0011876 
130. Pilton M, Varese F, Berry K, Bucci S. The relationship between dissociation and voices: A systematic literature review and meta-analysis. Clin Psychol $\operatorname{Rev}$ (2015) 40:138-55. doi: 10.1016/j.cpr.2015.06.004

131. Varese F, Barkus E, Bentall RP. Dissociation mediates the relationship between childhood trauma and hallucination-proneness. Psychol Med (2012a) 42:1025-36. doi: 10.1017/S0033291711001826

132. Perona-Garcelan S, Carrascoso-Lopez F, Garcia-Montes JM, DuctorRecuerda MJ, Lopez Jimenez AM, Vallina-Fernandez O, et al. Dissociative experiences as mediators between childhood trauma and auditory hallucinations. J Trauma Stress (2012a) 25:323-9. doi: 10.1002/jts.21693

133. Perona-Garcelan S, Garcia-Montes JM, Rodriguez-Testal JF, Lopez-Jimenez AM, Ruiz-Veguilla M, Ductor-Recuerda MJ, et al. Relationship between childhood trauma, mindfulness, and dissociation in subjects with and without hallucination proneness. J Trauma Dissociation (2014) 15:35-51. doi: 10.1080/15299732.2013.821433

134. Laddis A, Dell PF. Dissociation and psychosis in dissociative identity disorder and schizophrenia. J Trauma Dissociation (2012) 13:397-413. doi: $10.1080 / 15299732.2012 .664967$

135. Spitzer C, Haug HJ, Freyberger HJ. Dissociative symptoms in schizophrenic patients with positive and negative symptoms. Psychopathology (1997) 30:67-75. doi: 10.1159/000285031

136. Maggini C, Raballo A, Salvatore P. Depersonalization and basic symptoms in schizophrenia. Psychopathology (2002) 35:17-24. doi: 10.1159/000056211

137. Offen L, Thomas G, Waller G. Dissociation as a mediator of the relationship between recalled parenting and the clinical correlates of auditory hallucinations. Br J Clin Psychol (2003a) 42:231-41. doi: 10.1348/ 01446650360703357

138. Offen L, Waller G, Thomas G. Is reported childhood sexual abuse associated with the psychopathological characteristics of patients who experience auditory hallucinations? Child Abuse Negl (2003b) 27:919-27. doi: 10.1016/S0145-2134(03)00139-X

139. Kilcommons AM, Morrison AP. Relationships between trauma and psychosis: an exploration of cognitive and dissociative factors. Acta Psychiatr Scand (2005) 112:351-9. doi: 10.1111/j.1600-0447.2005.00623.x

140. Lysaker PH, Larocco VA. The prevalence and correlates of trauma-related symptoms in schizophrenia spectrum disorder. Compr Psychiatry (2008) 49:330-4. doi: 10.1016/j.comppsych.2007.12.003

141. Perona-Garcelan S, Cuevas-Yust C, Garcia-Montes JM, Perez-Alvarez M, Ductor-Recuerda MJ, Salas-Azcona R, et al. Relationship between selffocused attention and dissociation in patients with and without auditory hallucinations. J Nerv Ment Dis (2008) 196:190-7. doi: 10.1097/ NMD.0b013e318165c7c1

142. Perona-Garcelan S, Garcia-Montes JM, Cuevas-Yust C, Perez-Alvarez M, Ductor-Recuerda MJ, Salas-Azcona R, et al. A preliminary exploration of trauma, dissociation, and positive psychotic symptoms in a Spanish sample. $J$ Trauma Dissociation (2010) 11:284-92. doi: 10.1080/15299731003786462

143. Varese F, Barkus E, Bentall RP. Dissociative and metacognitive factors in hallucination-proneness when controlling for comorbid symptoms. Cognit Neuropsychiatry (2011) 16:193-217. doi: 10.1080/13546805.2010.495244

144. Perona-Garcelan S, Garcia-Montes JM, Ductor-Recuerda MJ, VallinaFernandez O, Cuevas-Yust C, Perez-Alvarez M, et al. Relationship of metacognition, absorption, and depersonalization in patients with auditory hallucinations. Br J Clin Psychol (2012b) 51:100-18. doi: 10.1111/j.20448260.2011.02015.x

145. Allen JG, Coyne L, Console DA. Dissociative detachment relates to psychotic symptoms and personality decompensation. Compr Psychiatry (1997) 38:327-34. doi: 10.1016/S0010-440X(97)90928-7
146. Renard SB, Huntjens RJ, Lysaker PH, Moskowitz A, Aleman A, Pijnenborg GH. Unique and Overlapping Symptoms in Schizophrenia Spectrum and Dissociative Disorders in Relation to Models of Psychopathology: A Systematic Review. Schizophr Bull (2017) 43:108-21. doi: 10.1093/schbul/ sbw063

147. Haddock G, McCarron J, Tarrier N, Faragher EB. Scales to measure dimensions of hallucinations and delusions: the psychotic symptom rating scales (PSYRATS). Psychol Med (1999) 29:879-89. doi: 10.1017/ S0033291799008661

148. Hoffman RE, Gueorguieva R, Hawkins KA, Varanko M, Boutros NN, Wu YT, et al. Temporoparietal transcranial magnetic stimulation for auditory hallucinations: safety, efficacy and moderators in a fifty patient sample. Biol Psychiatry (2005) 58:97-104. doi: 10.1016/j.biopsych.2005.03.041

149. Reich DB, Winternitz S, Hennen J, Watts T, Stanculescu C. A preliminary study of risperidone in the treatment of posttraumatic stress disorder related to childhood abuse in women. J Clin Psychiatry (2004) 65:1601-6. doi: 10.4088/JCP.v65n1204

150. Padala PR, Madison J, Monnahan M, Marcil W, Price P, Ramaswamy S, et al. Risperidone monotherapy for post-traumatic stress disorder related to sexual assault and domestic abuse in women. Int Clin Psychopharmacol (2006) 21:275-80. doi: 10.1097/00004850-200609000-00005

151. U.S. Department of Veteran Affairs and U.S. Department of Defense. (2017). VA/DOD Clinical Practice Guideline for the Management of Posttraumatic Stress Disorder and Acute Stress Disorder. (Washington, DC: Prepared by the Management of Posttraumatic Stress Disorder Work Group, with support from The Office of Quality, Safety and Value, VA, Washington, DC \& Office of Evidence Based Practice, U.S. Army Medical Command) Available: https://www.healthquality.va.gov/guidelines/MH/ptsd/ VADoDPTSDCPGFinal012418.pdf [Accessed June 30, 2018].

152. International Society for the Study of Trauma and Dissociation. Guidelines for treating dissociative identity disorder in adults, third revision. J Trauma Dissociation (2011) 12:115-87. doi: 10.1080/15299732.2011.537247

153. Kircher T, David A. Introduction. In: Kircher T, David A, editors. The Self in Neuroscience and Psychiatry. Cambridge, UK: Cambridge University Press (2003). doi: 10.1017/CBO9780511543708

154. Parnas J, Moller P, Kircher T, Thalbitzer J, Jansson L, Handest P, et al. EASE: Examination of Anomalous Self-Experience. Psychopathology (2005) 38:23658. doi: $10.1159 / 000088441$

155. Parnas J. Self and schizophrenia: A phenomenological perspective. In: Kircher T, David A, editors. The Self in Neuroscience and Psychiatry. Cambridge, UK: Cambridge University Press (2003). doi: 10.1017/ CBO9780511543708.012

156. Johns LC, van Os J. The continuity of psychotic experiences in the general population. Clin Psychol Rev (2001) 21:1125-41. doi: 10.1016/S0272-7358 (01)00103-9

Conflict of Interest: The authors declare that the research was conducted in the absence of any commercial or financial relationships that could be construed as a potential conflict of interest.

Copyright (c) 2020 Shinn, Wolff, Hwang, Lebois, Robinson, Winternitz, Öngür, Ressler and Kaufman. This is an open-access article distributed under the terms of the Creative Commons Attribution License (CC BY). The use, distribution or reproduction in other forums is permitted, provided the original author(s) and the copyright owner(s) are credited and that the original publication in this journal is cited, in accordance with accepted academic practice. No use, distribution or reproduction is permitted which does not comply with these terms. 